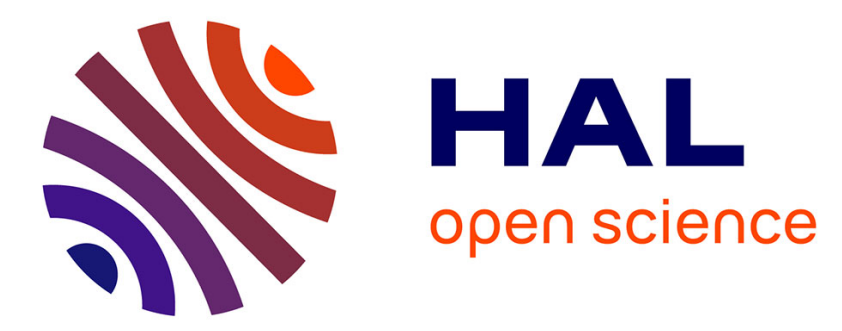

\title{
Tuning the nature and stability of self-assemblies formed by ester benzene 1,3,5-tricarboxamides: the crucial role played by the substituents
}

\author{
Alaric Desmarchelier, Bruno Giordano Alvarenga, Xavier Caumes, Ludovic \\ Dubreucq, Claire Troufflard, Martine Tessier, Nicolas Vanthuyne, Julien Idé, \\ Thomas Maistriaux, David Beljonne, et al.
}

\section{To cite this version:}

Alaric Desmarchelier, Bruno Giordano Alvarenga, Xavier Caumes, Ludovic Dubreucq, Claire Troufflard, et al.. Tuning the nature and stability of self-assemblies formed by ester benzene 1,3,5tricarboxamides: the crucial role played by the substituents. Soft Matter, 2016, 12, pp.7824-7838 10.1039/C6SM01601D . hal-01362222

\section{HAL Id: hal-01362222 \\ https://hal.sorbonne-universite.fr/hal-01362222}

Submitted on 8 Sep 2016

HAL is a multi-disciplinary open access archive for the deposit and dissemination of scientific research documents, whether they are published or not. The documents may come from teaching and research institutions in France or abroad, or from public or private research centers.
L'archive ouverte pluridisciplinaire HAL, est destinée au dépôt et à la diffusion de documents scientifiques de niveau recherche, publiés ou non, émanant des établissements d'enseignement et de recherche français ou étrangers, des laboratoires publics ou privés. 


\title{
Soft Matter
}

\section{Tuning the nature and stability of self-assemblies formed by ester benzene 1,3,5-tricarboxamides: the crucial role played by the substituents ${ }^{\dagger}$}

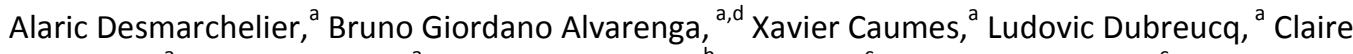
Troufflard, ${ }^{a}$ Martine Tessier, ${ }^{a}$ Nicolas Vanthuyne, ${ }^{b}$ Julien Idé, ${ }^{c}$ Thomas Maistriaux, ${ }^{c}$ David Beljonne, ${ }^{c}$ Patrick Brocorens, ${ }^{c}$ Roberto Lazzaroni, ${ }^{c}$ Matthieu Raynal ${ }^{* a}$ and Laurent Bouteiller ${ }^{a}$

As the benzene 1,3,5-tricarboxamide (BTA) moiety is commonly used as the central assembling unit for the construction of functionalized supramolecular architectures, strategies to tailor the nature and stability of BTA assemblies are needed. The assembly properties of a library of structurally-simple BTAs derived from amino dodecyl esters (ester BTAs, 13 members) have been studied, either in the bulk or in cyclohexane solutions, by means of a series of analytical methods (NMR, DSC, POM, FT-IR, UV-Vis, CD, ITC, high-sensitivity DSC, SANS). Two types of hydrogen-bonded species have been identified and characterized: the expected amide-bonded helical rods (or stacks) that are structurally similar to those formed by BTAs with simple alkyl side chains (alkyl BTAs), and ester-bonded dimers in which the BTAs are connected by means of hydrogen bonds linking the amide $\mathrm{N}-\mathrm{H}$ and the ester $\mathrm{C}=\mathrm{O}$. MM/MD calculations coupled with simulations of $\mathrm{CD}$ spectra allow for the precise determination of the molecular arrangement and of the hydrogen bond pattern of these dimers. Our study points out the crucial influence of the substituent attached on the amino-ester $\alpha$-carbon on the relative stabilities of the rod-like versus dimeric assemblies. By varying this substituent, one can precisely tune the nature of the dominant hydrogenbonded species (stacks or dimers) in the neat compounds and in cyclohexane over a wide range of temperatures and concentrations. In the neat BTAs, stacks are stable up to $213^{\circ} \mathrm{C}$ and dimers above $180^{\circ} \mathrm{C}$ whilst in cyclohexane stacks form at $c^{*}>3 \times 10^{-5} \mathrm{M}$ at $20^{\circ} \mathrm{C}$ and dimers are stable up to $80^{\circ} \mathrm{C}$ at $7 \times 10^{-6} \mathrm{M}$. Ester BTAs that assemble into stacks form a liquidcrystalline phase and yield gels or viscous solutions in cyclohexane, demonstrating the importance of controlling the structure of these assemblies. Our systematic study of these structurally-similar ester BTAs also allows for a better understanding of how a single atom or moiety can impact the nature and stability of BTA aggregates, which is of importance for the future development of functionalized BTA supramolecular polymers.
\end{abstract}

\section{Introduction}

Progress in supramolecular chemistry has allowed the expeditious construction of complex discrete or macromolecular structures through the design of well-defined non-covalent interactions. Supramolecular polymers, notably those forming precise and predictable one-dimensional (1-D) hydrogen-bonded assemblies, ${ }^{1-3}$ have attracted particular interest as a result of their stimuli-responsive and dynamic properties. Functional groups and hydrogen-bonded

Sorbonne Universités, UPMC Univ Paris 06, CNRS, Institut Parisien de Chimie Moléculaire, Equipe Chimie des Polymères, 4 Place Jussieu, F-75005 Paris, France. E-mail : matthieu.raynal@upmc.fr

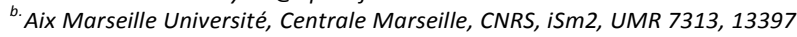
Marseille cedex 20 France

c. Service de Chimie des Matériaux Nouveaux, Université de Mons/Materia Nova, Place du Parc, 20, B-7000 Mons, Belgium

${ }^{d}$. Department of Physical-Chemistry, Institute of Chemistry, University of Campinas, Brazil

+ Electronic Supplementary Information (ESI) available: General procedures, (including sample preparation method and apparatus description), Figures S1 to S28, and synthesis and characterization of ester BTAs. See DOI: $10.1039 / x 0 x x 00000 x$ assembling units have been combined in the same monomeric entity $^{4}$ to favour the formation of well-defined 1-D aggregates in water $^{5-14}$ or in polar solvents, ${ }^{15,16}$ the preparation of selfsorting $^{17}$ or phase-segregating ${ }^{18-22}$ supramolecular materials, or to impart the resulting supramolecular polymers with new properties for applications as bioactive materials, ${ }^{23}$ conductive materials ${ }^{24}$ or catalysts. ${ }^{25-29}$

Functional groups but also alkyl groups, heteroatoms and aromatic rings located in close proximity of the assembly units $^{30-33}$ can affect adversely the stability of the assemblies and/or preclude the formation of a well-defined onedimensional structure for the resulting hydrogen-bonded supramolecular polymers. ${ }^{10,34}$ In contrast, such groups, can also positively modify the properties of the polymers by forming weak secondary interactions or by triggering less obvious modifications such as a different conformation of the side chains ${ }^{35}$ or assembly units. ${ }^{36,37}$ For example, we found that an ester group, located at the $\beta$-position of the urea assembly units of bisurea monomers, induces the formation of 


\section{Soft Matter}

\section{PAPER}

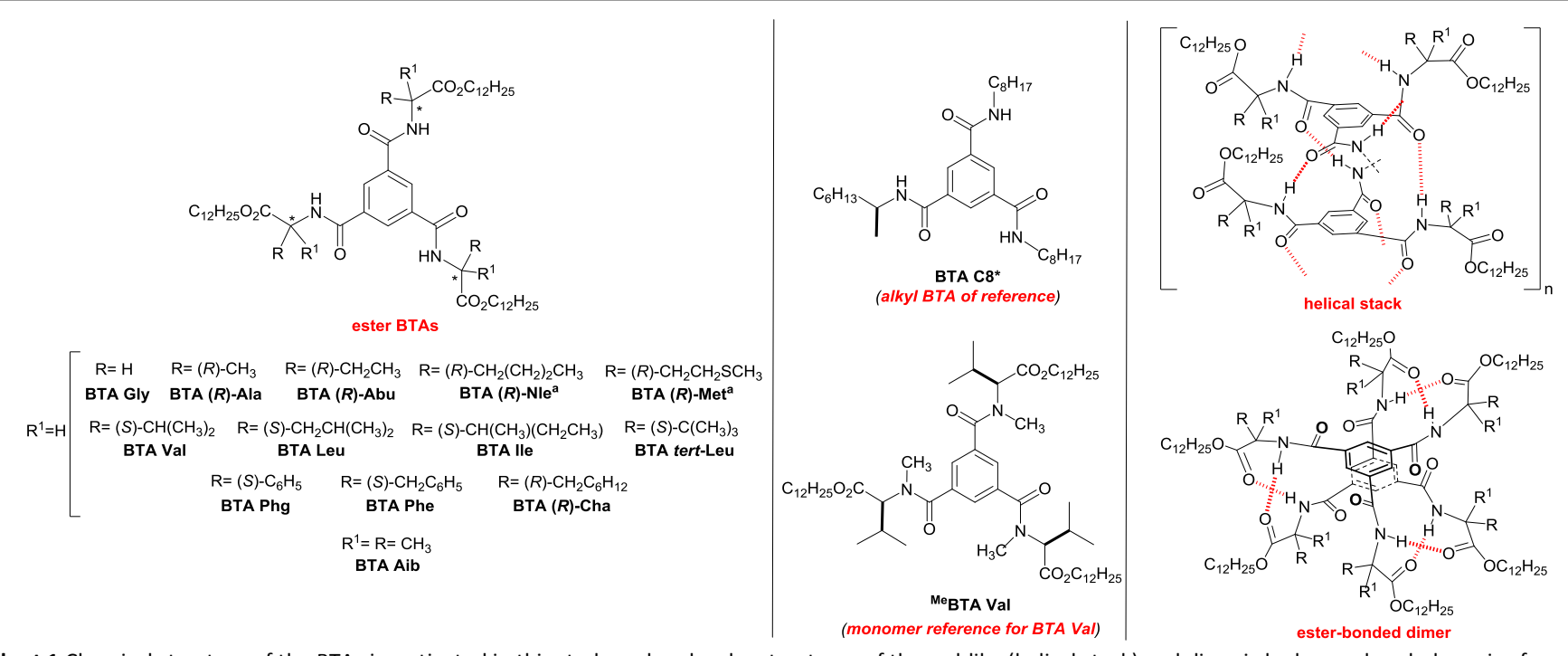

Chart 1 Chemical structure of the BTAs investigated in this study and molecular structures of the rod-like (helical stack) and dimeric hydrogen-bonded species formed by ester BTAs. ${ }^{2}$ The association behaviour of BTA Nle and BTA Met has also been investigated in order to verify that these ester BTAs provide enantiomeric hydrogenbonded species compared to BTA $(R)$-Nle and BTA $(R)$-Met respectively.

an alternative 1-D rod-like structure. ${ }^{38}$ It is also remarkable that the stability of this structure can be easily tuned by changing the nature of the substituent in the $\alpha$-position of the urea functions.

Such intriguing modifications of the supramolecular polymer properties upon subtle changes in the close environment of the hydrogen-bonded assembling units has also been observed for benzene-1,3,5-tricarboxamides (BTAs). ${ }^{39}$ BTAs are ubiquitous synthons in supramolecular chemistry due to their structural simplicity, the predictable mode of association of the monomers into rod-like structures and important applications as gels, ${ }^{40-45}$ liquid-crystalline materials, ${ }^{21,40,41,46-53}$ thin films with remnant polarization, ${ }^{54}$ additives for polymers, ${ }^{55-58} \mathrm{MRI}$ agents, ${ }^{59-62}$ chiral templates for Au NPs ${ }^{63}$ and catalysts. ${ }^{25-29}$ Meijer and colleagues have shown that the stability of the rod-like aggregates (or stacks) formed by BTAs bearing chiral methyl-alkyl side chains increases when the stereogenic center is closer to the amide functions. ${ }^{51}$ Such an effect is related to the different conformations adopted by the chiral chains which in turn affect the dihedral angle between the $\mathrm{C}=\mathrm{O}$ group and the aromatic ring of the BTA. ${ }^{35}$ The stability of the columnar, hexagonal, liquid-crystalline phase displayed by BTAs bearing alkyl side chains (alkyl BTAs) was also found to be governed by the nature of the alkyl chains (length, branching). ${ }^{52}$ Not only the stability but also the dynamics of the BTA supramolecular polymers in solution can be tuned upon slight variations in the structure of the peripheral chains. $^{12}$
BTAs derived from $\alpha$-amino esters ${ }^{43,45,64-70}$ (ester BTAs, see Chart 1) or bearing peptidic fragments ${ }^{71-76}$ present attractive features: i) a wide range of chiral pendant groups can be incorporated in the $\alpha$-position of the amide functions and ii) additional secondary interactions are expected between the pendant groups, which can be used to reinforce or weaken the helical structure. The X-ray structures of the BTAs derived from the methyl esters of (L)-valine, ${ }^{68}$ (L)-methionine, ${ }^{70}$ (L)-glutamic acid dimethyl ester, ${ }^{64}$ (L)-phenylalanine, ${ }^{68}(\mathrm{~L})$-tyrosine ${ }^{70}$ and of 4 repeating 2 -aminoisobutyric ester fragments ${ }^{71}$ revealed the formation of stacks only in the first three cases. Two previous studies on BTAs derived from the octyl esters of glycine, ${ }^{66}$ (L)isoleucine ${ }^{66}$ and (L)-phenylalanine ${ }^{66,67}$ mentioned their inability to form gels or long aggregates in apolar solvents. We recently revisited the association properties of ester BTAs and, contrary to our expectations, found that BTA Met and BTA Phe (Chart 1) do form long right-handed helical rods in cyclohexane solution. ${ }^{77}$ Intriguingly, BTA Nle, which is isosteric to BTA Met, only forms ester-bonded dimers under the same conditions (see the molecular structures in Chart 1). Our study also revealed that for BTA Met and BTA Phe, stacks and dimers are in competition in solution, the former being the major species at $\mathrm{mM}$ concentration and ambient temperature.

Intrigued by the unusual properties of that first set of ester BTAs, we now report a systematic study of the nature and stability of the hydrogen-bonded assemblies formed by an extensive set of ester BTAs (13 members, Chart 1) in the bulk or in cyclohexane solution. Ester BTAs mainly form two types of assemblies, stacks or dimers, as proved by means of several 


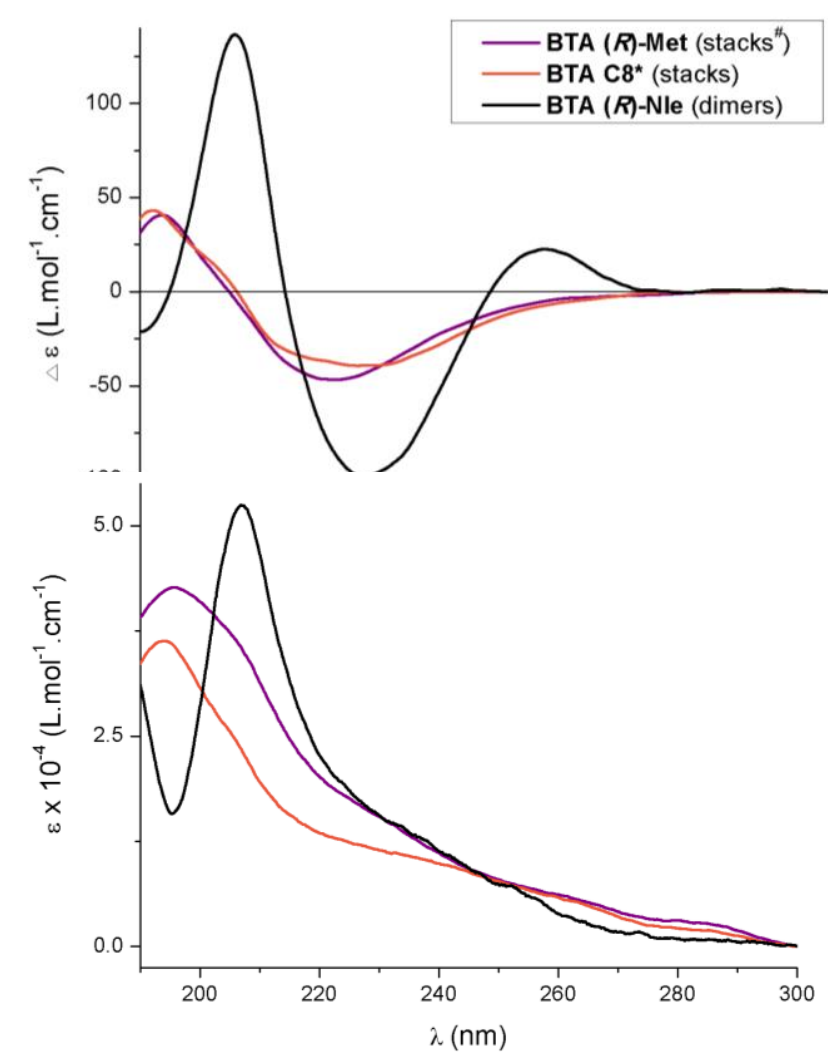

Fig. 1 Fingerprint $C D$ and UV characterization of stacks and dimers. Spectra for BTA $(\boldsymbol{R})$-Met $\left(2 \times 10^{-3} \mathrm{M}\right)$ BTA $(\boldsymbol{R})$-Nle $\left(5 \times 10^{-5} \mathrm{M}\right)$, and BTA C8* $\left(2 \times 10^{-3} \mathrm{M}\right)$ were
recorded in cyclohexane. At $2 \times 10^{-3} \mathrm{M}$ in cyclohexane, BTA (R)-Met recorded in cyclohexane. At $2 \times 10, \mathrm{M}$ in cyclohexane, BTA (R)-Met predominantly exists as stacks but
determined by FT-IR analyses (Fig. S21).

analytical techniques. The molecular arrangement and the hydrogen bond pattern of the dimers have been validated thanks to Molecular Mechanics/Molecular Dynamics (MM/MD) calculations and $\mathrm{CD}$ spectra simulations. The relative stability between stacks and dimers, as probed by calorimetric measurements and variable-temperature (VT) spectroscopic studies, can be finely tuned in the bulk and in solution by changing the nature of the substituent attached on the $\alpha$-carbon. Only the ester BTAs that aggregate into stacks form liquid-crystalline phases or viscous solutions, highlighting the importance of controlling the association properties of BTA monomers.

\section{Results}

\section{Library of ester benzene 1,3,5-tricarboxamides investigated}

We previously reported on the assembly properties of BTA Nle, ${ }^{77}$ BTA Met, ${ }^{77}$ BTA Phe ${ }^{77}$ and BTA $11 e^{29}$ and screened the ability of these BTAs and others (BTA (R)-Ala, BTA (R)-Abu, BTA Val, BTA Leu, BTA Phg) to act as enantiopure comonomers in the context of asymmetric catalysis. ${ }^{29}$ Here, we complete our library of ester BTAs (Chart 1) with the preparation of: i) two ester BTAs with a non-stereogenic $\alpha$ carbon (BTA Gly and BTA Aib), ii) BTA $(\boldsymbol{R})$-Cha to probe the influence of the phenyl rings in the assembly of BTA Phe, iii) BTA tert-Leu which possesses a bulky tertiobutyl group directly connected to the $\alpha$-carbon and iv) ${ }^{\text {Me }}$ BTA Val with the purpose of serving as a monomeric reference for BTA Val in the context of DOSY experiments (vide infra). BTA Gly, BTA Aib and BTA $(\boldsymbol{R})$-Cha were obtained following the same two-step procedure as that reported previously for the other ester BTAs, i.e., i) esterification of the commercial amino-acid with $\mathrm{pTsOH} \bullet \mathrm{H}_{2} \mathrm{O}$ and dodecanol and ii) amide bond formation by reacting the ester ammonium with trimesoyl chloride in the presence of $\mathrm{NEt}_{3}$. (S)-tert-Leucine did not react with dodecanol and pTsOH $\bullet \mathrm{H}_{2} \mathrm{O}$ even with prolonged reaction time and excess of the alcohol. In that case, the esterification was successfully accomplished by reacting $\mathrm{SOCl}_{2}$ and the amino acid in neat dodecanol. ${ }^{\text {Me }}$ BTA Val was prepared from BTA Val following a published procedure for the $\mathrm{N}$-methylation of amino acid derivatives with dimethyl sulfate. ${ }^{78}$ The new ester BTAs were obtained pure and fully characterized by ${ }^{1} \mathrm{H} N M R,{ }^{13} \mathrm{C}\left\{{ }^{1} \mathrm{H}\right\} \mathrm{NMR}$ and HMRS. Additionally, the optical purity of BTA $(R)$-Cha and BTA tert-Leu was measured by chiral HPLC: ee and de were higher than $99 \%$ in both cases.

Having this library of ester BTAs with dodecyl side chains in hand (Chart 1), we can precisely probe the influence on their assembly properties of: i) the ester function (comparison between BTA Gly and its analogous alkyl BTA reported in the literature), ${ }^{47}$ ii) the length of the linear alkyl chain connected to the $\alpha$-carbon (Me: BTA $(\boldsymbol{R})$-Ala, Et: BTA $(\boldsymbol{R})$-Abu, Bu: BTA Nle), iii) the sulfur heteroatom in BTA Met (compared to BTA Nle), iv) the bulky groups attached on the $\alpha$-carbon (i-Pr: BTA Val, $i$-Bu: BTA Leu, s-Bu: BTA lle, $t$-Bu: BTA tert-Leu, $\mathrm{CH}_{2} \mathrm{Cy}$ : BTA (R)-Cha), v) a pendant phenyl group (BTA Phg, BTA Phe) and vi) a secondary carbon in the $\alpha$-position of the amide groups (BTA Aib). BTA C8* is chosen as a reference for alkyl BTAs as its self-assembly properties, in bulk and in solution, have been described. ${ }^{51}$

Characterization of the hydrogen-bonded species: stacks and dimers

According to our initial communication ${ }^{77}$ and to the present systematic study (vide infra), ester BTAs of Chart 1 form two types of hydrogen-bonded species: stacks or dimers. We feel it is important to give a diagnostic characterization of both species in order to avoid erroneous assignments since notably both species are CD active. BTA $(\boldsymbol{R})$-Met and BTA $(\boldsymbol{R})$-Nle are selected as prototypal examples of ester BTAs that assemble into stacks and dimers, $\neq$ respectively, and their analytical signature is compared with that of BTA C8*, an alkyl BTA that forms stacks in the bulk and in methylcyclohexane. ${ }^{51}$

BTA ( $R$ )-Met and BTA C8* exhibit very similar Circular Dichroism (CD), UV-Vis and Fourier-Transform Infrared (FT-IR) spectra (Figs. 1 and 2) indicating that they form structurallysimilar left-handed helical stacks. ${ }^{35}$ More precisely, both compounds exhibit: i) a bisignated $C D$ signal (negative couplet $)^{79}$ with $\lambda^{-} \max \approx 225 \mathrm{~nm} \quad\left(\Delta \varepsilon \approx-45 \quad\right.$ L.mol $\left.{ }^{-1} . \mathrm{cm}^{-1}\right), \quad$ a crossover point at $204 \mathrm{~nm}$, and $\lambda^{+} \max \approx 193 \mathrm{~nm}(\Delta \varepsilon \approx+40$ L. $\left.\mathrm{mol}^{-1} \cdot \mathrm{cm}^{-1}\right)$, ii) a broad UV absorption band with a maximum at $\lambda \approx 195 \mathrm{~nm}$ which is the signature of excitonically-coupled aromatic rings of stacked BTAs, ${ }^{80}$ and iii) FT-IR absorption bands at $v \approx 3230 \mathrm{~cm}^{-1}$ (bonded $\mathrm{N}-\mathrm{H}$ ), $v \approx 1640 \mathrm{~cm}^{-1}$ (bonded amide $\mathrm{C}=\mathrm{O}$, amide I vibrational mode) and $\mathrm{v} \approx 1560 \mathrm{~cm}^{-1}$ 


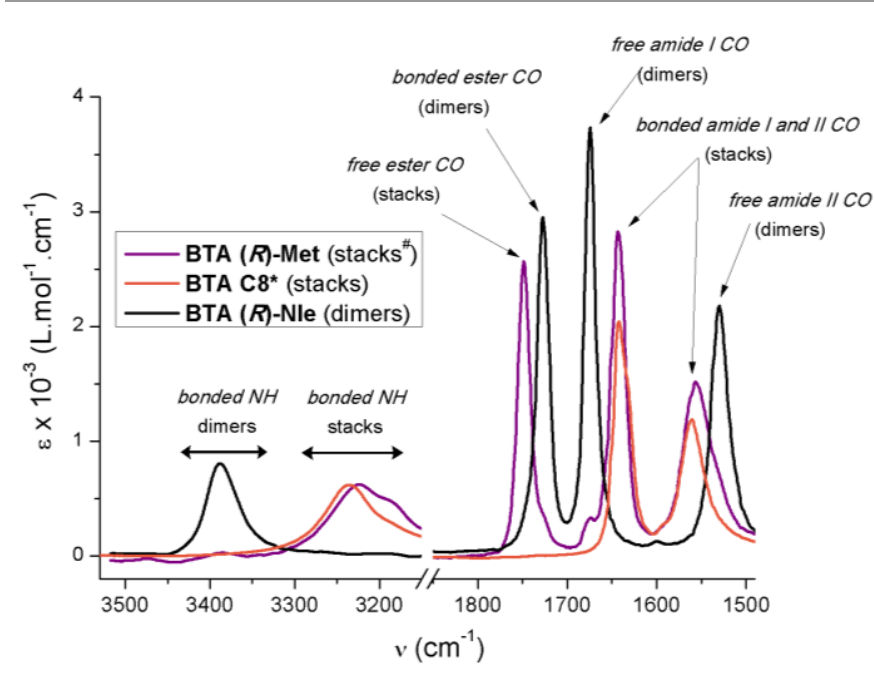

Fig. 2 Fingerprint FT-IR characterization of stacks and dimers. Spectra were recorded at a concentration of $10^{-2} \mathrm{M}$ in cyclohexane for BTA $(\boldsymbol{R})$-Met and BTA
$(\boldsymbol{R})$-Nle and in decaline for BTA C $\mathbf{8}^{*}\left(20^{\circ} \mathrm{C}\right)$. Zoom on the N-H and C=O regions. $(\boldsymbol{R})-\mathrm{Nle}$ and in decaline for BTA $\mathrm{CB}^{*}\left(20^{\circ} \mathrm{C}\right)$. Zoom on the $\mathrm{N}-\mathrm{H}$ and $\mathrm{C}=\mathrm{O}$ regions.
At $10^{-2} \mathrm{M}$ in cyclohexane, BTA $(\boldsymbol{R})$-Met predominantly exists as stacks but ca. $5 \%$ At $10^{-2} \mathrm{M}$ in cyclohexane, BTA $(\boldsymbol{R})$-Met
of dimers are also present (Fig. S21).

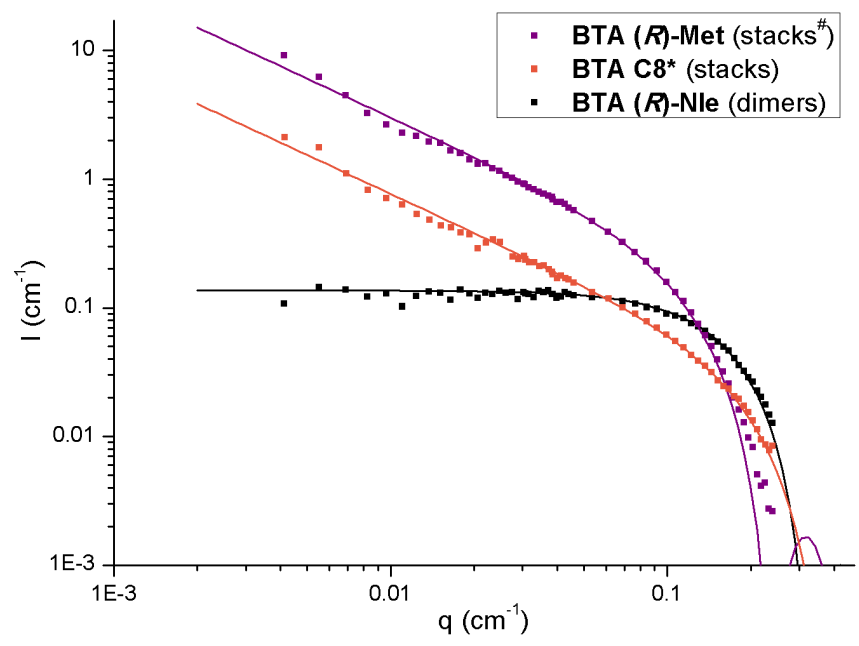

Fig.3 SANS characterization of stacks and dimers. SANS analyses of BTA $(\boldsymbol{R})$-Me (5.7 g. $\left.\mathrm{L}^{-1}, 5.1 \times 10^{-3} \mathrm{M}\right)$, BTA C8* $\left(2.2 \mathrm{~g} \cdot \mathrm{L}^{-1}, 6.1 \times 10^{-3} \mathrm{M}\right)$ and BTA $(\boldsymbol{R})$-Nle $\left(10.6 \mathrm{~g} . \mathrm{L}^{-1}\right.$ $10.1 \times 10^{-3} \mathrm{M}$ ) were performed in $\mathrm{C}_{6} \mathrm{D}_{12}$ at $20^{\circ} \mathrm{C}$. \# At $5.1 \times 10^{-3} \mathrm{M}$ in cyclohexane BTA $(\boldsymbol{R})$-Met predominantly exists as stacks but $c a .11 \%$ of dimers are als present (Fig. S21). The curves are fitted according to the form factor for rigid rods with a circular cross section and a uniform scattering length density for BTA $(\boldsymbol{R})$-Met and BTA C8* or for spheres with a uniform scattering length density for
BTA $(R)$-Nle. Results of the fits: $r=16.0 \AA$ and $9.9 \AA$ for the cylindrical objects BTA $(\boldsymbol{R})$-Nle. Results of the fits: $r=16.0$ A and 9.9 A for the cylindrical objects
formed by BTA $(\boldsymbol{R})$-Met and BTA C8* respectively and $\mathrm{r}=13.5 \AA$ and $M=2000$ g.mol ${ }^{-1}$ for the spheres formed by BTA $(R)$-Nle. For the latter, it yields $M_{\text {spherical }}$ object $/ \mathrm{M}_{\text {monomer }}=1.9$ consistent with the formation of dimeric species.

(bonded amide $\mathrm{C}=\mathrm{O}$, amide II vibrational mode) which indicate that the $\mathrm{N}-\mathrm{H}$ protons are bonded to the carbonyl groups of the amide functions. BTA (R)-Met and BTA C8* both form cylindrical objects with a length $>200 \AA$ and radii of $16.0 \AA$ and $9.9 \AA$, respectively, as determined by Small-Angle Neutron Scattering (SANS) analyses (Fig. 3). The values of these radii are consistent with the presence of a single BTA molecule in the cross-section. ${ }^{1} \mathrm{H}$ NMR spectra of BTA $(\boldsymbol{R})$-Met $\left(\mathrm{C}_{6} \mathrm{D}_{12}, 5.1 \times 10^{-3}\right.$ $\mathrm{M})$ and BTA C8* $\left(\mathrm{C}_{6} \mathrm{D}_{12}, 10^{-2} \mathrm{M}\right)$ display very broad peaks and in the case of BTA C8* only signals corresponding to protons of the alkyl chains can be distinguished (Fig. S1). The presence of broad lines in these NMR spectra is indicative of the formation of aggregates and only moieties located far from the associating groups (e.g. the end of the alkyl chains) yield

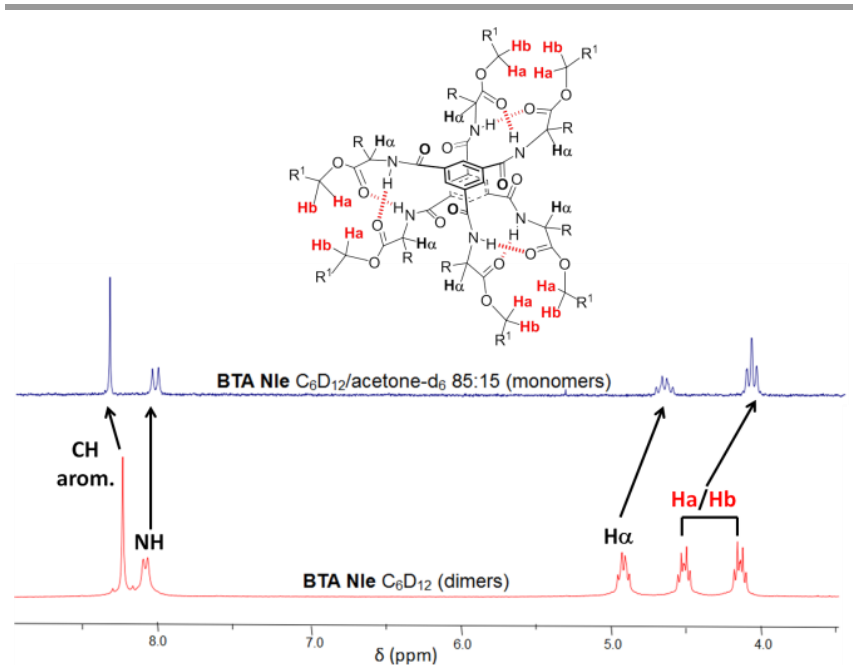

Fig. $4{ }^{1} \mathrm{H}$ NMR spectra of BTA $(\boldsymbol{R})$-Nle $\left(10^{-2} \mathrm{M}\right)$ in $\mathrm{C}_{6} \mathrm{D}_{12}$ (bottom) and in
$\mathrm{C}_{6} \mathrm{D}_{12}$ acetone-d $85: 15$ (top) at $20^{\circ} \mathrm{C}$. Zoom on the region between 3.5 and 9.0 ppm (see full spectrum in Fig. S1).
spe

discernible signals. ${ }^{81,82}$ In the case of BTA $(\boldsymbol{R})$-Met, lowintensity peaks corresponding to $\mathrm{N}-\mathrm{H}$ and aromatic $\mathrm{C}-\mathrm{H}$ protons are also detected (see inset in Fig. S1). These signals probably correspond to the small amount of dimers (ca. 11\%) of BTA $(\boldsymbol{R})$-Met that are in equilibrium with the stacks in these conditions as determined by FT-IR analyses (Fig. S21).

BTA $(\boldsymbol{R})$-Nle show spectroscopic analyses with the following signature (Figs. 1 and 2): i) an intense $C D$ signal with three maxima at $\lambda^{+} \approx 255 \mathrm{~nm}\left(\Delta \varepsilon=23 \mathrm{~L} \cdot \mathrm{mol}^{-1} \cdot \mathrm{cm}^{-1}\right), \lambda^{2} \approx 226 \mathrm{~nm}(\Delta \varepsilon=-98$ L. $\left.\mathrm{mol}^{-1} \cdot \mathrm{cm}^{-1}\right)$ and $\lambda^{+} \approx 205 \mathrm{~nm}\left(\Delta \varepsilon=137\right.$ L. $\left.\mathrm{mol}^{-1} \cdot \mathrm{cm}^{-1}\right)$ and ii) FT-IR absorption bands at $v=3389 \mathrm{~cm}^{-1}$ (bonded $\mathrm{N}-\mathrm{H}$ ), $v=1728 \mathrm{~cm}^{-1}$ (bonded ester $\mathrm{C}=0$ ), ${ }^{77,83} \mathrm{v}=1675 \mathrm{~cm}^{-1}$ (free amide CO, amide I vibrational mode) and $v=1530 \mathrm{~cm}^{-1}$ (free amide CO, amide II vibrational mode) which indicate that the $\mathrm{N}-\mathrm{H}$ protons are bonded to the carbonyl groups of the ester functions, the $\mathrm{C}=\mathrm{O}$ of the amide functions being free. In order to probe the size of the hydrogen-bonded species formed by BTA $(\boldsymbol{R})$-Nle, we performed DOSY analyses. We selected BTA Val, an ester BTA that assembles into dimers in cyclohexane, similarly to BTA (R)-Nle (vide infra and Figs. S22 to S25) and Me ${ }^{\text {BTA Val (see }}$ Chart 1), the same ester BTA with methylated amide functions, chosen as the monomeric reference (see the SI for more details). The hydrodynamic radius, of the assemblies formed by BTA Val, as calculated with the Stokes-Einstein equation for spherical objects, is $1.4 \pm 0.1$ times that of the monomer (Fig. S2). Even though this value is in accordance with the presence of small species, DOSY experiments do not allow us to discriminate between dimeric $\left(r_{\mathrm{h}}\right.$ dimer $/ r_{\mathrm{h}}$ monomer $\left.=1.26\right)$ or trimeric $\left(r_{\mathrm{h} \text { trimer }} / r_{\mathrm{h} \text { monomer }}=1.44\right)$ species. The scattering curve of BTA $(\boldsymbol{R})$-Nle and BTA Val are perfectly fitted with a form factor for spherical objects having 1.9 times the molar mass of the monomer (SANS analysis, Figs. 3 and S24). The dimeric nature of BTA $(\boldsymbol{R})$-Nle is thus confirmed on the basis of DOSY and SANS analyses. In contrast to BTA $(R)$-Met and BTA C8*, the ${ }^{1} \mathrm{H}$ NMR spectrum of BTA $(\boldsymbol{R})$-Nle $\left(\mathrm{C}_{6} \mathrm{D}_{12}, 10^{-2} \mathrm{M}\right)$ presents well-resolved signals (Figs. 4 and S1). The disruption of the dimer into the monomer can be followed upon adding incremental amounts of acetone- $d_{6}$ to the $C_{6} D_{12}$ solution, since 
protons $\mathrm{Ha}$ and $\mathrm{Hb}$ are diastereotopic in the ester-bonded dimer but not in the monomer. $15 \%$ of acetone- $d_{6}$ is required to get full dissociation of the dimer. ${ }^{77}$ The diastereotopicity of $\mathrm{Ha}$ and $\mathrm{Hb}$ (and probably of the other methylene protons of the dodecyl side chains) indicates a lower symmetry for the alkyl chains in the dimeric structure compared to the monomer. Additionally, in the dimer, the aromatic protons are upfield shifted $(\Delta \delta=-0.13 \mathrm{ppm})$ as a result of the presence of an aromatic interaction between the BTA rings ( $3.58 \AA$ between the centroids of the aromatic rings in the modelled structure, vide infra).

Spectroscopic and scattering analyses allow a clear distinction between the rod-like helical structure formed by BTA $(\boldsymbol{R})$-Met and the dimeric structure formed by BTA $(\boldsymbol{R})$-Nle. Both species possess diagnostic CD/UV signals and FT-IR absorption bands that will enable a rapid identification of the nature of the assemblies formed by these ester BTAs regardless of the experimental conditions (bulk or solution, concentration, solvent). The fingerprint characterization of stacks and dimers can obviously be extended to other ester BTAs, whichever substituent is attached on the $\alpha$-carbon, with the exception of those possessing an additional chromophore (BTA Phg, BTA Phe) which are expected to exhibit a different $C D$ and UV signature (vide infra).

\section{Molecular modelling of the dimeric structure}

$\mathrm{MM} / \mathrm{MD}$ calculations have been performed in order to obtain a more precise representation of the dimeric structure (molecular arrangement and hydrogen bond pattern) formed by ester BTAs. BTA Nle was selected as the ester BTA. Based on the analyses mentioned above, dimeric structures in which the $\mathrm{N}-\mathrm{H}$ protons are bonded to the ester carbonyls have been investigated. Two possible molecular arrangements have been envisioned: i) a structure in which the $\mathrm{C}=\mathrm{O}$ and $\mathrm{N}-\mathrm{H}$ groups located on the same arm of the first BTA are hydrogen-bonded to the $\mathrm{N}-\mathrm{H}$ proton and $\mathrm{C}=\mathrm{O}$ groups, respectively, belonging to the same arm of the second BTA, yielding a dimer in which the non-covalent interactions are crossed ("crossing structure", Fig. 5a), and ii) a structure in which the $\mathrm{C}=\mathrm{O}$ and $\mathrm{N}-\mathrm{H}$ groups located on the same arm of the first BTA are hydrogen-bonded to the $\mathrm{N}-\mathrm{H}$ and $\mathrm{C}=\mathrm{O}$ groups, respectively, belonging to two different arms of the second BTA, yielding a dimer in which the hydrogen bond network rotates clockwise or counterclockwise ("spiral structure", Fig. 5b). Energy-minimized structures are shown in Fig. 5. For the "crossing structure" its pseudo mirror-image structure has also been constructed ("inverse crossing structure"). In the two "crossing structures", the chirality induced by the hydrogen-bonded network of the peripheral chains to the central BTA aromatic rings is inversed $((P)$ versus $(M)$ helicity, Fig. S4a). In contrast, inverting the sense of rotation of the hydrogen-bond network (i.e. clockwise vs. counter-clockwise) in the "spiral structure" does not generate a different structure since a pseudo-inversion centre is located in between the two BTA rings of the "spiral structure". Whilst the "crossing structure" and the "spiral structure" display similar potential energies, the "inverse crossing structure" is far less stable (by more than 10
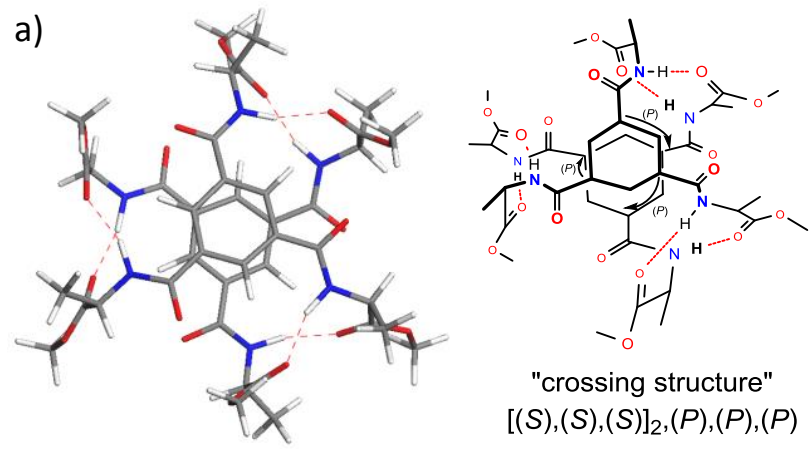

"crossing structure" $[(S),(S),(S)]_{2},(P),(P),(P)$

b)
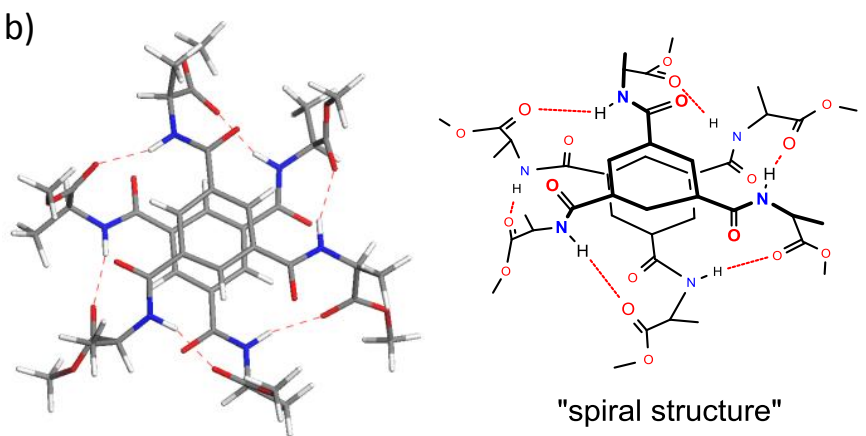

"spiral structure"

c)

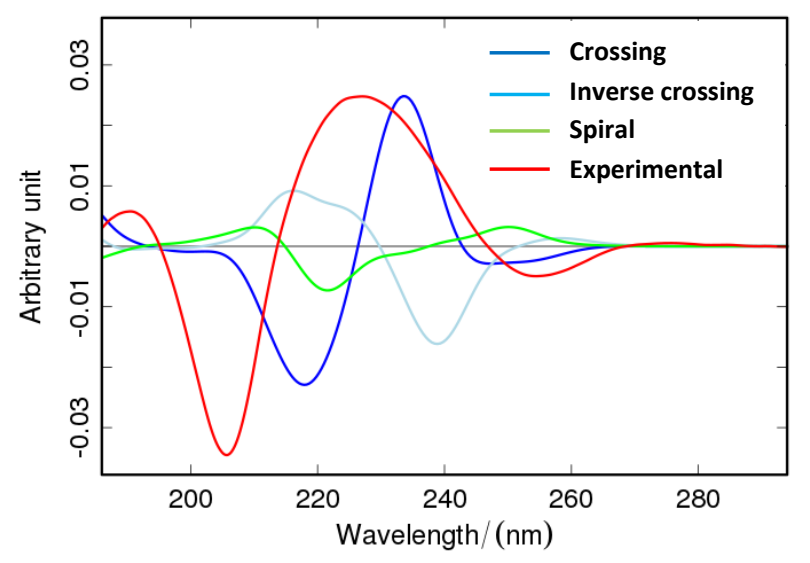

Fig. 5 Energy-minimized structures of the "crossing structure " (a) and of the "spiral structure " (b) of BTA Nle. Arrows in the "crossing structure" represen the sense of chiral induction of the three hydrogen-bonded 10-membered ring to central BTA aromatic rings (all )(P)). For the sake of clarity, the butyl groups attached on the $\alpha$-carbons and the dodecyl groups of the ester side chains were replaced by methyl groups. Simulated CD spectra of the "crossing structure", the inverse crossing structur
CD spectrum of BTA Nle (c).

kcal.mol ${ }^{-1}$, Fig. S4b). This is consistent with the preferred sense of chiral induction observed in hydrogen-bonded ferrocene peptides, ${ }^{84}$ metallated phosphane peptides ${ }^{85-88}$ and stacked ester BTAs, ${ }^{64,65,70}$ for which (L)-amino acids induce ( $P$ )-helical chirality of the central aromatic ring. The Molecular dynamics calculations and the simulations of the $C D$ spectra clearly establish the "crossing structure" as the most plausible molecular arrangement for the dimers formed by ester BTAs. This is based on the observation that the hydrogen-bond network remains stable for the "crossing structure". On the contrary, in the "spiral structure", the amide C=O are sufficiently close to the $\mathrm{N}-\mathrm{H}$ groups to compete with the ester groups for the formation of hydrogen bonds. As a result, the conformations generated in the course of the dynamics typically have between one and three hydrogen bonds with 
Table 1 Transition temperature $\left({ }^{\circ} \mathrm{C}\right)$ and corresponding enthalpies $\left(\mathrm{kJ} . \mathrm{mol}^{-1}\right)$ of ester BTAs obtained by DSC measurements. ${ }^{(\mathrm{a})}$

\begin{tabular}{|c|c|c|c|c|c|c|c|c|}
\hline Ester BTA & $\mathrm{K}$ (or M) & $T_{m}(\Delta H)$ & K2 (or M1) & $T(\Delta H)$ & $\mathrm{M} 2=\mathrm{Col}_{\mathrm{ho}}$ & $T_{c l}(\Delta H)$ & I & Remarks \\
\hline BTA Gly & - & $10(5)$ & - & $18(1)$ & & & - & no mesophase $>20^{\circ} \mathrm{C}(\mathrm{POM})$ \\
\hline BTA (R)-Ala & - & $11(30)^{(b)}$ & - & $19(1)$ & - & $132(12)$ & • & \\
\hline BTA $(R)$-Abu & $\bullet$ & $6(43)$ & & & • & $165(26)$ & • & \\
\hline BTA Nle & $\bullet$ & $-16(34)$ & & & .(c) & $136(23)$ & • & $\begin{array}{c}\mathrm{I} \rightarrow \mathrm{Col}_{\mathrm{ho}} 143^{\circ} \mathrm{C}(\mathrm{POM}) \\
137^{\circ} \mathrm{C}<\mathrm{Col}_{\mathrm{ho}} \rightarrow \mid<142^{\circ} \mathrm{C}(\mathrm{FT}-\mathrm{IR})\end{array}$ \\
\hline BTA Met & $\bullet$ & $-13(31)$ & & & .(c) & $189(43)$ & • & $\mathrm{I} \rightarrow \mathrm{Col}_{\mathrm{ho}} 189^{\circ} \mathrm{C}$ (POM) \\
\hline BTA Val & • & $9(18)$ & - & $69(10)$ & - & $158(35)$ & • & \\
\hline BTA Leu & • & $-17(18)$ & & & • & $138(26)$ & • & \\
\hline BTA lle & - & $-1(21)$ & - & 21 (9) & - & $131(27)$ & - & \\
\hline BTA tert-Leu & • & $-27(11)$ & • & $58(6)$ & • & $134(20)^{(\mathrm{d})}$ & - & \\
\hline BTA Phg & - & $-3(10)$ & & & - & $74(7)$ & - & \\
\hline BTA Phe & • & $-28(9)$ & & & .(c) & $168(39)$ & • & $\mathrm{I} \rightarrow \mathrm{Col}_{\mathrm{ho}} 171^{\circ} \mathrm{C}(\mathrm{POM})$ \\
\hline BTA $(R)$-Cha & • & $-20^{(\mathrm{e})}$ & & & & & - & no mesophase $>20^{\circ} \mathrm{C}$ (POM) \\
\hline BTA Aib & - & $-2(23)$ & - & $42(6)$ & . (c) & $213(45)$ & - & $\mathrm{I} \rightarrow \mathrm{Col}_{\mathrm{ho}} 214^{\circ} \mathrm{C}(\mathrm{POM})$ \\
\hline
\end{tabular}

(a) All DSC data are derived from the second heating run $\left(20^{\circ} \mathrm{C} \cdot \mathrm{min}^{-1}\right) . \mathrm{K}=$ crystalline phase, $\mathrm{M} 1, \mathrm{M} 2=$ mesophase, I=isotropic phase. $T_{m}=$ melting temperature. $T_{c}=$ clearing temperature. $\mathrm{Col}_{\mathrm{ho}}=$ columnar hexagonal mesophase. (b) BTA (R)-Ala exhibits complex phase transitions with three overlapping peaks observed with maxima at $-12^{\circ} \mathrm{C}$ (broad peak), $7^{\circ} \mathrm{C}$ and $11^{\circ} \mathrm{C}$. (c) mesophases observed by POM upon cooling the isotropic phase. (d) A shoulder is observed. (e) $\mathrm{T}_{\mathrm{g}}$ (glass transition).

the amide groups, (see the radial distribution of the hydrogen bonds, Fig. S4c), in contrast to what is found experimentally. Along the same line, only the calculated CD spectrum of the "crossing structure" reproduces qualitatively the experimental CD spectrum of BTA Nle (Fig. 5c), in particular the -/+/- pattern observed in the $200-260 \mathrm{~nm}$ region. In contrast, only weak CD signals are present in the simulated $C D$ spectrum of the "spiral structure".

\section{Nature and stability of the assemblies in the bulk}

We first probe the influence of the substituent attached on the $\alpha$-carbon on the nature and stability of the assemblies formed by ester BTAs (Chart 1 ) in the bulk. Ester BTAs are gum-like solids at room temperature except BTA Gly which is a crystalline solid. The thermal properties of ester BTAs have been probed by DSC (Table 1) as was done previously for alkyl BTAs $^{21,36,37,42-49}$ and a series of BTAs extended with dipeptide fragments bearing mesogenic groups. ${ }^{72}$ Our data for BTA C8* $\left(2^{\text {nd }}\right.$ heating run, $\mathrm{M} 250$ I with $\Delta H=40 \mathrm{~kJ} \mathrm{~mol}^{-1}$ ) are consistent with those reported in the literature (M 255 I with $\Delta H=27$ kJ. $\left.\mathrm{mol}^{-1}\right){ }^{51}$ The DSC traces $\left(20^{\circ} \mathrm{C} \cdot \mathrm{min}^{-1},-70^{\circ} \mathrm{C}<\mathrm{T}<200^{\circ} \mathrm{C}\right.$ except for BTA Aib $-80^{\circ} \mathrm{C}<\mathrm{T}<250^{\circ} \mathrm{C}$ ) of ester BTAs show a reversible peak at $-28^{\circ} \mathrm{C}<\mathrm{T}<11^{\circ} \mathrm{C}$ which is likely related to crystallization or a glass transition. BTA Gly and BTA $(\boldsymbol{R})$-Cha fail to recrystallize after melting (see DSC traces Fig. S5).

First, the nature of the assemblies of ester BTAs above their melting point (or glass transition) was determined by FT-IR, CD and UV-Vis analyses. At $20^{\circ} \mathrm{C}$ (i.e., above their melting point), all the ester BTAs of Chart 1 are assembled into stacks except BTA Gly and BTA (R)-Cha. This can be deduced from the diagnostic bands in their FT-IR spectra (Fig. S6) and UV spectra (Fig. S7). In most cases, their CD spectra (Fig. S7) also closely resemble those of BTA $(\boldsymbol{R})$-Met (Fig. 1) but significantly different CD spectra are also observed for: i) BTA Phg and BTA Phe and ii) BTA (R)-Ala and BTA tert-Leu. In the former two compounds, the difference is likely due to the presence of additional chromophores that contribute to the CD signal. In the latter two compounds, it can be presumed that the nature of the stacks formed by BTA $(\boldsymbol{R})$-Ala and BTA tert-Leu differ from that of BTA $(\boldsymbol{R})$-Met or that interactions occur between the stacks in the bulk, which modify the shape and intensity of the $C D$ spectra.

In striking contrast, the analyses on BTA $(R)$-Cha at $20^{\circ} \mathrm{C}$ clearly show the presence of ester-bonded dimers as the dominant species. The FT-IR spectra indicate that BTA $(\boldsymbol{R})$-Cha is assembled into dimers in both its crystalline (Fig. S6) and melted phases (Fig. S8). Dimers are still present (in combination with monomers) at the highest temperature investigated $\left(192^{\circ} \mathrm{C}\right)$. At low temperature, i.e., below the glass transition observed in DSC, aggregates start to form (observation of a broad band at $c a .3250 \mathrm{~cm}^{-1}$ ) but dimers remain the major species even at $-60^{\circ} \mathrm{C}$. Dimers are thermodynamically stable since similar FT-IR spectra were obtained before and after the heating process and after annealing the samples several days at $20^{\circ} \mathrm{C}$.

The complexity of the FT-IR spectrum displayed by BTA Gly in its crystalline state $\left(20^{\circ} \mathrm{C}\right)$ prevents a precise assignment of the nature of the assemblies: whilst absorption bands at $3400 \mathrm{~cm}^{-1}$ and $1714 \mathrm{~cm}^{-1}$ might be attributed to dimers, other bands are also present in the $\mathrm{N}-\mathrm{H}$ and $\mathrm{C}=\mathrm{O}$ regions which correspond to an unidentified type of aggregates (Fig. S6). The ratio between these bands does not vary significantly for various samples of BTA Gly (Fig. S9) corresponding to solids collected after evaporation of the solvent $\left(\mathrm{CH}_{2} \mathrm{Cl}_{2}\right.$ :AcOEt $\left.1: 1\right)$, after recrystallization ( $\mathrm{MeCN}$ ) and after filtration of the precipitate obtained after several days from a 20 wt\% cyclohexane solution of BTA Gly (vide infra). Clearly, BTA Gly does not aggregate into stacks in its solid phase. BTA $(\boldsymbol{R})$-Cha and BTA Gly exhibit weak enthalpies for the phase transitions $\left(\Delta \mathrm{H} \leq 5 \mathrm{~kJ} \mathrm{~mol}^{-1}\right)$ in the solid state, suggesting that only limited changes occur in the nature of their assemblies. BTA $(\boldsymbol{R})$-Cha and BTA Gly do not form a liquid crystalline phase either, as 


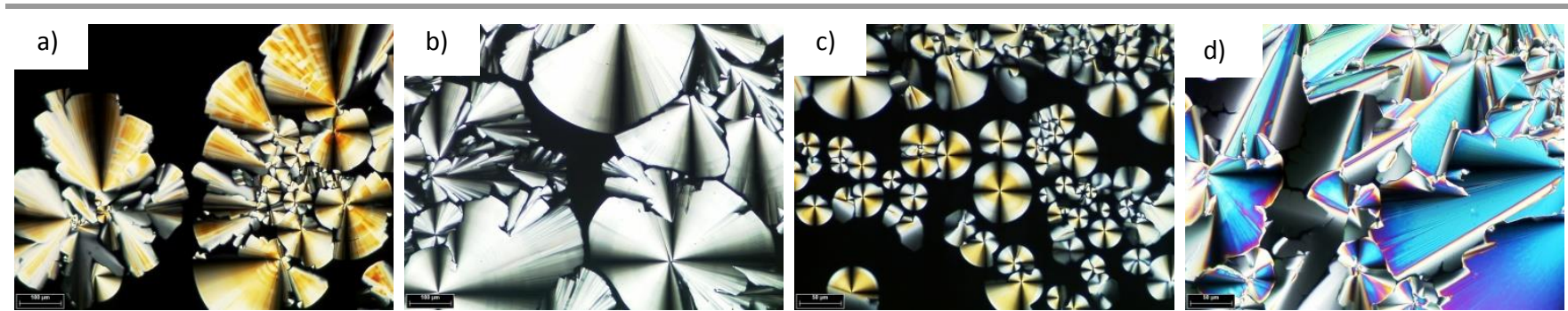

Fig. 6 Optical textures for BTA Nle $\left(a, 143^{\circ} \mathrm{C}\right)$, BTA Met $\left(\mathrm{b}, 189^{\circ} \mathrm{C}\right)$, BTA Phe $\left(\mathrm{c}, 171^{\circ} \mathrm{C}\right)$ and $\mathrm{BTA}$ Aib $\left(\mathrm{d}, 214^{\circ} \mathrm{C}\right)$ obtained upon slow cooling from the isotropic phase.

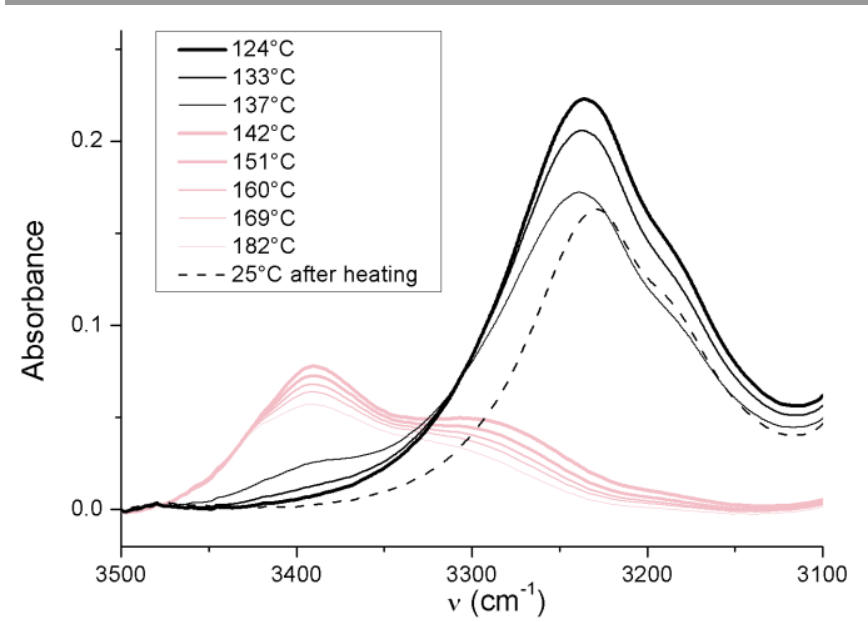

Fig. 7 FT-IR spectra of BTA Nle in the bulk ( $\mathrm{KBr}$ plates) above and below its clearing temperature $\left(T_{C /(D S C)}=136^{\circ} \mathrm{C}\right)$. Zoom on the $\mathrm{N}-\mathrm{H}$ region. Heating rate: solid to $182^{\circ} \mathrm{C}$ ) compared to that at $124^{\circ} \mathrm{C}$ is likely due loss of matter during the heating process.

evidenced by the absence of textures in the Polarized Optical Microscopy (POM) images.

In contrast, all the other ester BTAs show an intense transition well above their melting point $\left(74^{\circ} \mathrm{C} \leq T_{c l} \leq 213^{\circ} \mathrm{C}\right)$ and POM analyses confirmed that this transition occurs between a mesophase and an isotropic phase. We verified that the clearing temperature observed by $\mathrm{POM}$ is close to the transition temperature measured by DSC for BTA Nle, BTA Met, BTA Phe and BTA Aib (see remarks in Table 1). These ester BTAs show a pseudo-focal conic texture (Fig. 6) which resembles that displayed by BTA $\mathbf{C 8}^{*}$ and is typical of a columnar hexagonal mesophase $\left(\mathrm{Col}_{\mathrm{ho}}\right)^{51,52}$ The texture is maintained at $20^{\circ} \mathrm{C}$, indicating that these ester BTAs are liquid crystalline above their melting temperature. In some cases (BTA (R)-Ala, BTA Val, BTA Ile, BTA tert-Leu and BTA Aib), other phase transitions are observed in between the melting and clearing temperatures, which highlight the complex polymorphism for these compounds. The assignment of these transitions (solid-solid transitions or LC-LC transitions) is out of the scope of this paper.

We were interested in probing the nature of the hydrogenbonded species present above the clearing temperature $\left(T_{c l}\right)$ in order to determine whether it is possible to correlate the stability of the rod-like structure with $T_{c l}$. Accordingly, FT-IR spectra were recorded for BTA Nle between $124^{\circ} \mathrm{C}$ and $182^{\circ} \mathrm{C}$
(Fig. 7 and Fig. S10, heating rate: $1^{\circ} \mathrm{C} \cdot \mathrm{min}^{-1}$ ). A sharp transition is observed between $137^{\circ} \mathrm{C}$ and $142^{\circ} \mathrm{C}$, as shown by the disappearance of the FT-IR absorption band at $v=3258 \mathrm{~cm}^{-1}$ corresponding to long stacks and by the concomitant emergence of a broad new band at $v=3391 \mathrm{~cm}^{-1}$ appended with several shoulders $\left(v \approx 3450 \mathrm{~cm}^{-1}, 3300 \mathrm{~cm}^{-1}\right.$ and 3200 $\mathrm{cm}^{-1}$ ). The transition temperature measured by FT-IR ( $T_{c / \text { FT }-}$ ${ }_{I R}=139.5^{\circ} \mathrm{C}$ ) is consistent with that obtained by DSC $\left(T_{c /(\mathrm{DSC})}=136^{\circ} \mathrm{C}\right)$. Above the transition, BTA Nle exists as a mixture of different species corresponding to ester-bonded dimers (diagnostic signals at $v=3391 \mathrm{~cm}^{-1}$ and $v=1739 \mathrm{~cm}^{-1}$ ) as well as another unidentified hydrogen-bonded species $(\mathrm{N}-\mathrm{H}$ absorption bands at $v \approx 3450 \mathrm{~cm}^{-1}$ and $v \approx 3300 \mathrm{~cm}^{-1}$ ). Above its clearing temperature, BTA Nle is thus not monomeric but consists of hydrogen-bonded aggregates which are optically isotropic. For a related alkyl BTA, Schmidt and co-workers observed the existence of aggregates above the clearing temperature, which broke up slowly with an increase in temperature. ${ }^{52}$ Our results are consistent with their findings except that, in our case, ester-bonded dimers are the dominant species above $T_{c l}$.

The FT-IR spectrum recorded at $25^{\circ} \mathrm{C}$ after heating the solid above the clearing temperature only contains the signals characteristic of the rod-like structure. Accordingly, stacks are the thermodynamically-favoured species in the bulk for all the ester BTAs of Chart 1 except BTA Gly and BTA (R)-Cha.

\section{Nature of the assemblies and stability of the stacks in cyclohexane}

By means of complementary techniques, we were able to probe the self-assembly properties of ester BTAs in cyclohexane over a wide range of concentrations and temperatures. Firstly, the nature of the assemblies at $20^{\circ} \mathrm{C}$ and different concentrations was determined by $C D$ and UV-Vis $\left(\mathrm{c} \leq 2 \times 10^{-3} \mathrm{M}\right)$ and by FT-IR, SANS and ${ }^{1} \mathrm{H}$ NMR $\left(\mathrm{c}>2 \times 10^{-3} \mathrm{M}\right)$ analyses. On the basis of these analyses, we hereinafter sort the ester BTAs of Chart 1 into two categories depending on their ability to form stacks, or not, at high concentration. Actually, in a simpler, qualitative way, these categories can be deduced from the ability (or not) of ester BTAs to form a gel or a viscous solution in cyclohexane: only BTAs that form long stacks can yield viscoelastic solutions. ${ }^{40-45}$ Next, the relative stability of stacks and dimers in cyclohexane was determined by means of calorimetric analyses, Isothermal Titration Calorimetry (ITC) and high-sensitivity Differential Scanning 


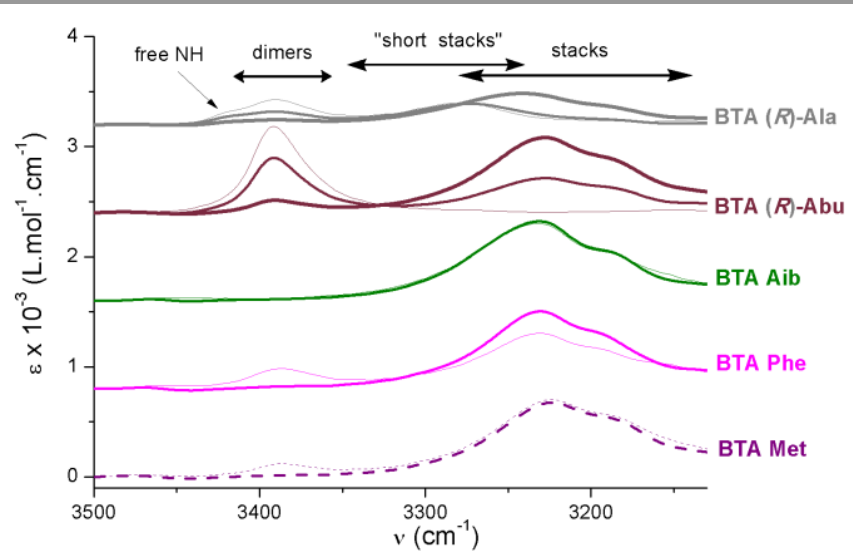

Fig. 8 FT-IR spectra of BTA Met, BTA Phe, BTA Aib, BTA $(R)$-Abu and BTA $(R)$-Ala in cyclohexane at $20^{\circ} \mathrm{C}$. Concentrations $=5 \times 10^{-3} \mathrm{M}$ (thin lines), $5 \times 10^{-2} \mathrm{M}$ (thick lines) and $2 \times 10^{-1} \mathrm{M}$ (very thick line, only for BTA $(\boldsymbol{R})$-Abu and BTA $(\boldsymbol{R})$-Ala). Zoom on the $\mathrm{N}-\mathrm{H}$ region. Spectra of BTA Aib are almost independent of concentration.
Spectra are shown with an offset of $800 \mathrm{~L}^{-\mathrm{mol}^{-1}} \mathrm{~cm}^{-1}$.

Calorimetry (DSC) and by variable-temperature spectroscopic studies (CD, UV-Vis, FT-IR analyses).

Gel properties and viscosimetry measurements Heating is not required to solubilise ester BTAs in cyclohexane (20 wt\% solutions) except for BTA Gly. ${ }^{\S, \S}$ Among the ester BTAs of Chart 1, only the solutions of BTA Met, BTA Aib, BTA Phe, BTA $(\boldsymbol{R})$-Abu and BTA $(\boldsymbol{R})$-Ala appear viscous and only BTA Met yields a self-standing gel (see pictures in Fig. S11). The relative viscosity of the solutions at different concentrations was measured for a set of ester BTAs (Fig. S12). From the measurements, the ability of the ester BTAs to form viscous solutions decreases in the following order: BTA Met $>$ BTA Aib $>$ BTA Phe > BTA $(R)$-Abu > BTA $(R)$-Ala > > all the other ester BTAs of Chart 1.

BTAs that form stacks at high concentration [BTA Met, BTA Phe, BTA Aib, BTA (R)-Abu and BTA (R)-Ala].

FT-IR analyses at $20^{\circ} \mathrm{C}$ show that dimers of BTA Met, BTA Phe, BTA $(\boldsymbol{R})$-Abu and BTA $(\boldsymbol{R})$-Ala, which are present in different ratios at $5 \times 10^{-3} \mathrm{M}$, transform into stacks upon increasing the concentration (Fig. 8). For BTA Aib, only stacks are observed by FT-IR even at $5 \times 10^{-3} \mathrm{M}$. Obviously, the amount of dimers at $5 \times 10^{-3} \mathrm{M}$ strongly depends on the nature of the ester BTAs: dimers correspond to $0 \%, 11 \%, 18 \%, 100 \%$ and $100 \%$ of the assemblies formed by BTA Aib, BTA Met, BTA Phe, BTA $(R)$ Abu and BTA $(R)$-Ala, respectively. BTA $(R)$-Abu and BTA $(R)$ Ala form stacks at a concentration that is at least two orders of magnitude higher than that of BTA Aib, BTA Met and BTA Phe. For BTA $(\boldsymbol{R})$-Abu, stacks are only detected for concentrations above $2.5 \times 10^{-2} \mathrm{M}$ and dimers (ca. $15 \%$ ) are still present at a concentration as high as $0.2 \mathrm{M}$ (Fig. S13). For BTA (R)-Ala, dimers transform into stacks at $c \geq 0.1 \mathrm{M}$ via the formation of an unidentified intermediate species characterized by $\mathrm{N}-\mathrm{H}$ absorption bands at $v=3410 \mathrm{~cm}^{-1}$ (free $\mathrm{N}-\mathrm{H}$ ) and $v \approx 3285 \mathrm{~cm}^{-1}$ ( $\mathrm{N}-\mathrm{H}$ bonded to amide $\mathrm{C}=\mathrm{O}$, see full spectra in Fig. S14). Based on the facts that the hydrogen bonds in the unidentified species are weaker that in the stacks and that free $\mathrm{N}-\mathrm{H}$ bonds are observed concomitantly to this species, it is possible that this unidentified species corresponds to "short stacks". This species is also likely formed by BTA Gly (vide infra).

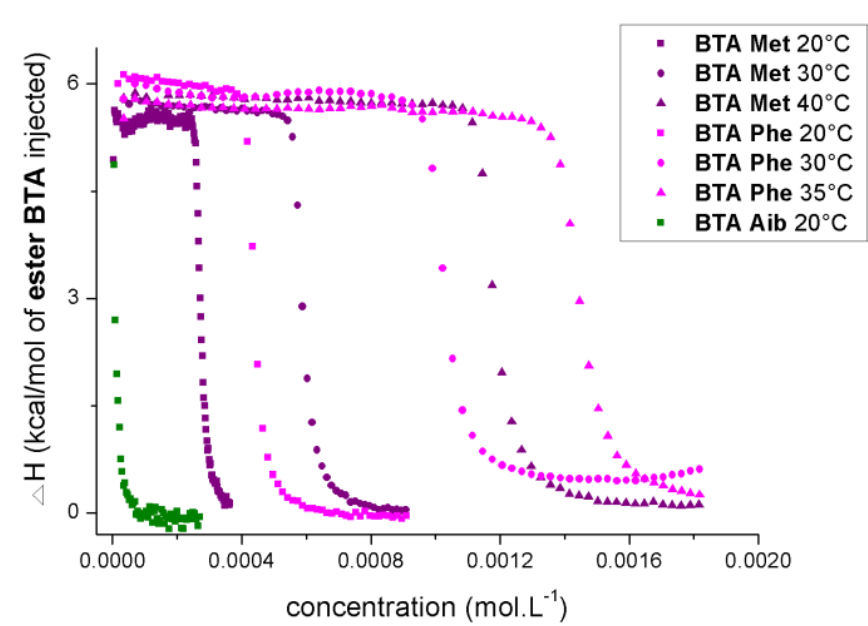

Fig. 9 Transition between stacks and dimers for BTA Met, BTA Phe and BTA Aib in cyclohexane as determined by ITC. ITC enthalpograms are obtained for este BTA concentration in the cell at the given temperature.

The critical concentration $\left(c^{*}\right)$, i.e., the concentration for which stacks predominate over dimers in cyclohexane solution, has been determined at $20^{\circ} \mathrm{C}$ by FT-IR for BTA $(R)$-Abu and BTA (R)-Ala and by ITC for BTA Aib, BTA Met and BTA Phe. ITC experiments (Fig. 9) yield the following critical concentrations: $c^{*}=2.8 \times 10^{-4} \mathrm{M}, 4.4 \times 10^{-4} \mathrm{M}$ and $3.0 \times 10^{-5} \mathrm{M}$ for BTA Met, BTA Phe and BTA Aib, respectively, whilst the FT-IR analyses (Figs. S13 and S14) give $c^{*} \approx 8 \times 10^{-2} \mathrm{M}$ for both BTA $(\boldsymbol{R})$-Abu and BTA (R)-Ala. Thus, BTA Aib forms stacks at a concentration that is one order of magnitude lower than that of BTA Met and BTA Phe and more than three orders of magnitude lower than that of BTA $(R)$-Abu and BTA $(R)$-Ala.

The nature of the species below and above the critical concentration was probed for these ester BTAs by means of CD and UV-Vis (Fig. S15, $20^{\circ} \mathrm{C}$ ), SANS (Fig. S16, $25^{\circ} \mathrm{C}$ ) and ${ }^{1} \mathrm{H} N M R$ (Fig. S17, $25^{\circ} \mathrm{C}$ ) analyses. For BTA (R)-Abu and BTA (R)-Ala, the formation of stacks as the main species above their $C^{*}$ is supported by the previously mentioned FT-IR analyses (Fig. 8) as well as by viscosimetry measurements (Fig. S11). For BTA Aib, BTA Met and BTA Phe, SANS and ${ }^{1} \mathrm{H}$ NMR are consistent with the FT-IR data and viscosimetry measurements and confirm that stacks are the mains species formed above their $c^{*}$. As expected from their FT-IR data, BTA Met and BTA Phe (CD and UV-Vis analyses) and BTA ( $R$ )-Abu (CD, UV-Vis, SANS and ${ }^{1} \mathrm{H}$ NMR analyses) predominantly form dimers below their $c^{*}$. For BTA Aib, the critical concentration is too low to enable the full transition to be observed (stacks only partially dissociate even at the lowest concentration investigated, $\left.5 \times 10^{-5} \mathrm{M}\right)$. The identification of the main species formed by BTA $(\boldsymbol{R})$-Ala below its $c^{*}$ is not trivial. Spectroscopic and scattering analyses (including FT-IR data in Figs. 8 and S14) are not consistent with dimers being the unique hydrogen-bonded species. Indeed, fitting the scattering curve obtained by SANS analysis for BTA (R)-Ala (ca. $10^{-2} \mathrm{M}$, Fig. S16) with a form factor for spheres yields a radius and a molar mass larger than those expected for dimers $\left(\mathrm{M}_{\text {spherical object }} / \mathrm{M}_{\text {monomer }}=4.8\right)$. Additionally, the ${ }^{1} \mathrm{H}$ NMR spectra recorded between $2 \times 10^{-3} \mathrm{M}$ and $5 \times 10^{-2} \mathrm{M}$ in $\mathrm{C}_{6} \mathrm{D}_{12}$ show that the singlet corresponding to aromatic 


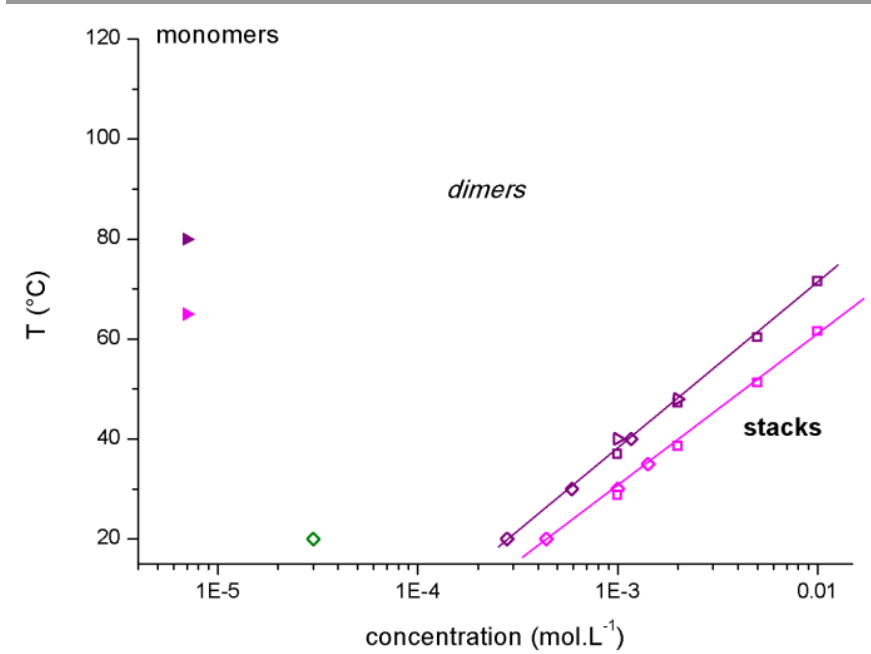

Fig. 10 Pseudo-phase diagrams of BTA Met (purple) and BTA Phe (magenta) in cyclohexane. The critical concentration obtained for BTA Aib (olive) at $20^{\circ} \mathrm{C}$ has been plotted for comparison. $T_{e}$ and $c^{*}$ have been determined by VT-CD
(triangle), high-sensitivity DSC (square) and ITC (diamond) analyses. The transition temperature between dimers and monomers $T^{* *}$ (full triangles) has been measured by $C D$ in methylcyclohexane. The lines are drawn to guide the eye.

protons is upfield shifted whilst the signal related to the $\mathrm{N}-\mathrm{H}$ protons is deshielded upon going to higher concentrations (Fig. S18). This is in accordance with the formation of "short stacks" since both aromatic and hydrogen bond interactions are expected to be involved in these aggregates. All these analyses are consistent with BTA $(\boldsymbol{R})$-Ala existing as a mixture of dimers and "short stacks" below its $C$ *.

Having established the nature of the hydrogen-bonded species formed by these ester BTAs at ambient temperature below and above their $c^{*}$, we then probed the relative stability of stacks and dimers in cyclohexane by means of calorimetric analyses (ITC and high-sensitivity DSC) and by variabletemperature spectroscopic studies (CD, UV-Vis, FT-IR analyses). The transition for BTA Aib occurs at a too low concentration (or high temperature, Figs. S16) and inversely that of BTA (R)-Abu and BTA (R)-Ala appears at a too high concentration (or low temperature) to be consistently assessed on a wide range of concentrations and temperatures. In contrast, for BTA Met and BTA Phe, the structural transition between stacks and dimers can be followed by many analytical techniques. ITC experiments performed at different temperatures (Fig. 9) provide $c^{*}$ values at temperatures up to $40^{\circ} \mathrm{C}$. High-sensitivity DSC experiments performed at different concentrations $\left(1 \times 10^{-3} \mathrm{M} \leq c^{*} \leq 10^{-2} \mathrm{M}\right)$ show endothermal peaks corresponding to the transition $\left(\Delta \mathrm{H}^{*} \approx 5 \mathrm{kcal} . \mathrm{mol}^{-1}\right)$ and yield elongation temperatures $\left(T_{e}\right.$, Fig. S19). ${ }^{80}$ The ellipticity measured by $\mathrm{CD}$ for $1 \times 10^{-3} \mathrm{M}$ and $2 \times 10^{-3} \mathrm{M}$ solutions of BTA Met $(\lambda=255 \mathrm{~nm})$ shows a clear variation at a temperature that is consistent with the elongation temperature determined by high-sensitivity DSC experiments (Fig. S20). Finally, the FT-IR absorbance at $\mathrm{v} \approx 3230 \mathrm{~cm}^{-1}$ (bonded $\mathrm{N}-\mathrm{H}$ in stacks) decreases sharply at the elongation temperature concomitantly with the appearance of signals for the dimers (Fig. S21). Based on these data, we can establish the pseudo-phase diagrams of BTA Met and BTA Phe which delineate the predominance domains of
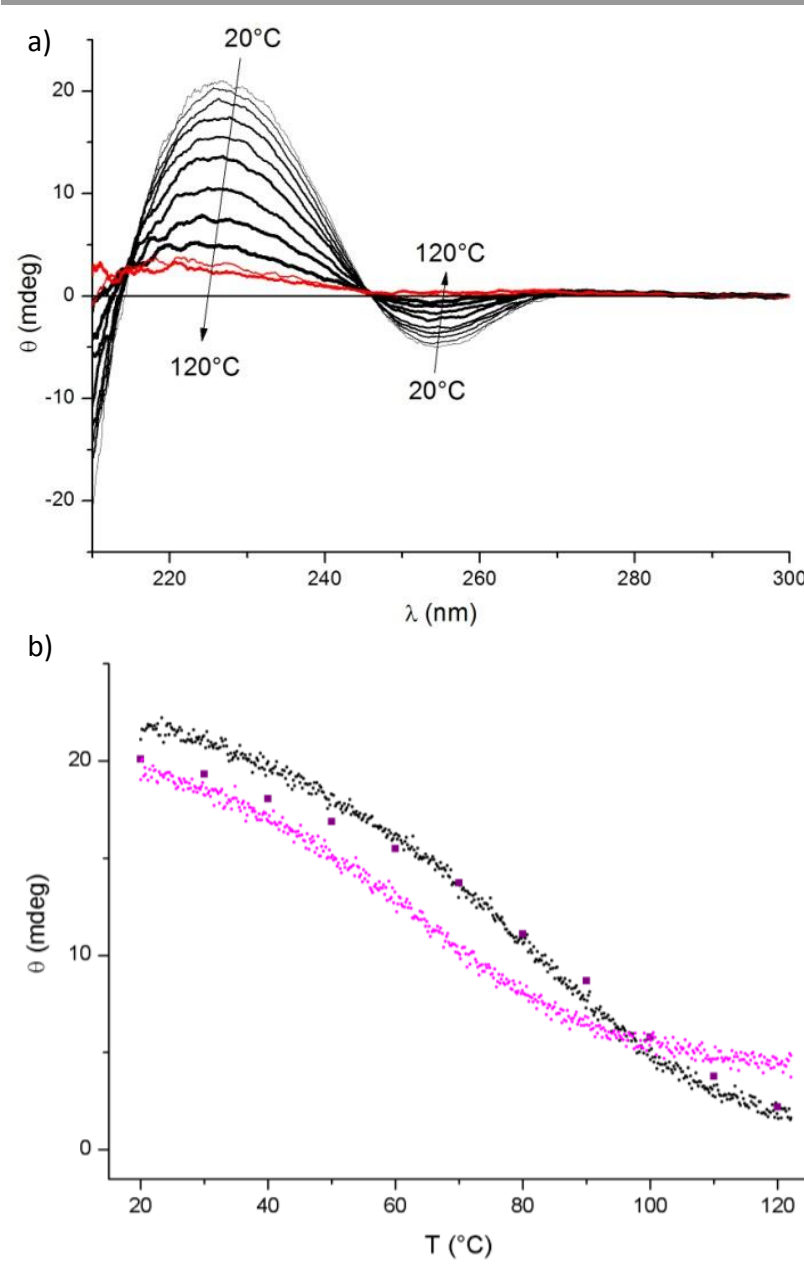

Fig. 11 Transition between dimers and monomers as determined by $\mathrm{CD}$ experiments. a) CD spectra of BTA Nle between $20^{\circ} \mathrm{C}$ and $120^{\circ} \mathrm{C}$ in methylcyclohexane $\left(c=7 \times 10^{-6} \mathrm{M}\right)$. b) Plot of the ellipticity monitored at $225 \mathrm{~nm}$ versus the temperature for BTA Nle (black dots), BTA Phe (magenta dots) and BTA Met (purple squares). For BTA Met, the ellipticity has been measured every $10^{\circ} \mathrm{C}$ while it has been measured $c a$. every $0.2^{\circ} \mathrm{C}$ for BTA Phe and BTA Nle. In al cases, the heating rate is $1^{\circ} \mathrm{C} \mathrm{min}^{-1}$.

stacks and dimers (Fig. 10). On the basis of the whole set of analytical data, the stability of the stacks in cyclohexane decreases in the following order: BTA Aib > BTA Met > BTA Phe $>$ BTA $(R)$-Abu $\approx$ BTA $(R)$-Ala.

$B T A s$ that assemble into dimers only.

BTA Nle, BTA Val, BTA Leu, BTA lle, BTA tert-Leu, BTA Phg and BTA $(\boldsymbol{R})$-Cha form dimers as the only hydrogen-bonded species in cyclohexane even at a concentration as high as $5 \times 10^{-2} \mathrm{M}$ (FT-IR analyses, Fig. S22). UV-Vis $\left(5 \times 10^{-5} \mathrm{M}\right.$, Fig. S23), CD $\left(5 \times 10^{-5} \mathrm{M}\right.$, Fig. S23), SANS (ca. $10^{-2} \mathrm{M}$, Fig. S24) and ${ }^{1} \mathrm{H}$ NMR $\left(10^{-2} \mathrm{M}\right.$, Fig. S25) analyses corroborate the formation of the ester-bonded dimer for these ester BTAs.

\section{Case of BTA Gly.}

BTA Gly shows a different association behaviour compared to the other ester BTAs of Chart 1. The FT-IR spectra recorded at different concentrations (from $5 \times 10^{-3} \mathrm{M}$ to $10^{-1} \mathrm{M}$, Fig. S26) indicate the formation, in addition to dimers, of a hydrogenbonded species that may correspond to "short stacks", similar to those characterized for BTA $(\boldsymbol{R})$-Ala (N-H absorption bands at $v=3410 \mathrm{~cm}^{-1}$ and $\left.v \approx 3285 \mathrm{~cm}^{-1}\right)$. The SANS $\left(M_{\text {spherical }}\right.$ object $/ M_{\text {monomer }}=4.5$, Fig. S27) and ${ }^{1} \mathrm{H}$ NMR (Fig. S18) analyses are consistent with the formation of objects larger than dimers. 
However, these "short stacks" do not transform into long stacks to a great extent upon increasing the concentration, since the $10 \mathrm{wt} \%$ cyclohexane solution of BTA Gly is not viscous (Fig. S12).

\section{Stability of the dimers in methylcyclohexane}

Previously, we found that the ester-bonded dimers of BTA Nle are very stable and cannot be totally disrupted even at $70^{\circ} \mathrm{C}$ and $\mathrm{c}=1.25 \times 10^{-5} \mathrm{M}$ in cyclohexane. ${ }^{77}$ We were also intrigued by the fact that for an ester BTA closely related to BTA Phe (with octyl instead of dodecyl ester side chains in our case), Meijer, Palmans and co-workers observed a transition between a species whose CD signal is diagnostic of dimers, and another $\mathrm{CD}$-active (unidentified) species at $90^{\circ} \mathrm{C}$ in methylcyclohexane at $\mu \mathrm{M}$ concentrations. ${ }^{67}$ We performed similar experiments with BTA Phe, BTA Met and BTA Nle: the CD spectra of $7 \times 10^{-6}$ $\mathrm{M}$ solutions were recorded between $20^{\circ} \mathrm{C}$ and $120^{\circ} \mathrm{C}$ in methylcyclohexane instead of cyclohexane in order to observe the full dissociation of the ester-bonded dimers (Fig. 11a for BTA Nle and Fig. S28 for BTA Phe and BTA Met). For the three ester BTAs, the CD signal that is the signature of dimers (negative peak at $c a .254 \mathrm{~nm}$ and positive peak at $c a .225 \mathrm{~nm}$ ) gradually decreases upon raising the temperature. At temperatures above $100^{\circ} \mathrm{C}$, the negative peak at $254 \mathrm{~nm}$ has totally disappeared but a residual positive $C D$ signal remains at $225 \mathrm{~nm}$. The presence of an isodichroic point $(\lambda \approx 245 \mathrm{~nm})$ indicates that the transition involves no intermediate species. The $C D$ signal of the species above $100^{\circ} \mathrm{C}$, a single Cotton effect with a maximum at $c a .220 \mathrm{~nm}$, is similar for the three ester BTAs and closely resembles that of the unidentified species detected by Meijer and colleagues. In fact, this species very likely corresponds to monomers of ester BTAs since it only exhibits a weak Cotton effect corresponding to the main electronic transition. ${ }^{\S \S}$ We precisely probed the transition between dimers and monomers by monitoring the ellipticity at $\lambda=225 \mathrm{~nm}$ and $\lambda=254 \mathrm{~nm}$ between $20^{\circ} \mathrm{C}$ and $120^{\circ} \mathrm{C}\left(1^{\circ} \mathrm{C} \cdot \mathrm{min}^{-1}\right.$, Fig. $11 \mathrm{~b}$ and Fig. S28). Comparing the plots of the ellipticity versus the temperature for the three ester BTAs shows that the dimers of BTA Met and BTA Nle are equally stable $\left(T^{* *} \approx 80^{\circ} \mathrm{C}\right)$ and more stable that the dimers of BTA Phe $\left(T^{* *} \approx 65^{\circ} \mathrm{C}\right)$.

\section{Discussion}

Our in-depth experimental and computational study gives a precise overview on the self-assembly properties of ester BTAs of Chart 1 at the molecular and macroscopic scale. These properties are summed up in Table 2.

Ester BTAs mainly form two types of hydrogen-bonded species, stacks and dimers, which can be easily distinguished by their distinct spectroscopic and scattering signatures. The nature of the substituent attached on the $\alpha$-carbon has little influence on the spectroscopic signals characteristic of dimers but can impact the $\mathrm{CD}$ and UV-Vis signals of stacks (e.g. compare the CD and UV-Vis data of the stacks of BTA Met and BTA Phe, Fig. S7 and Fig. S15). We also note that stacks
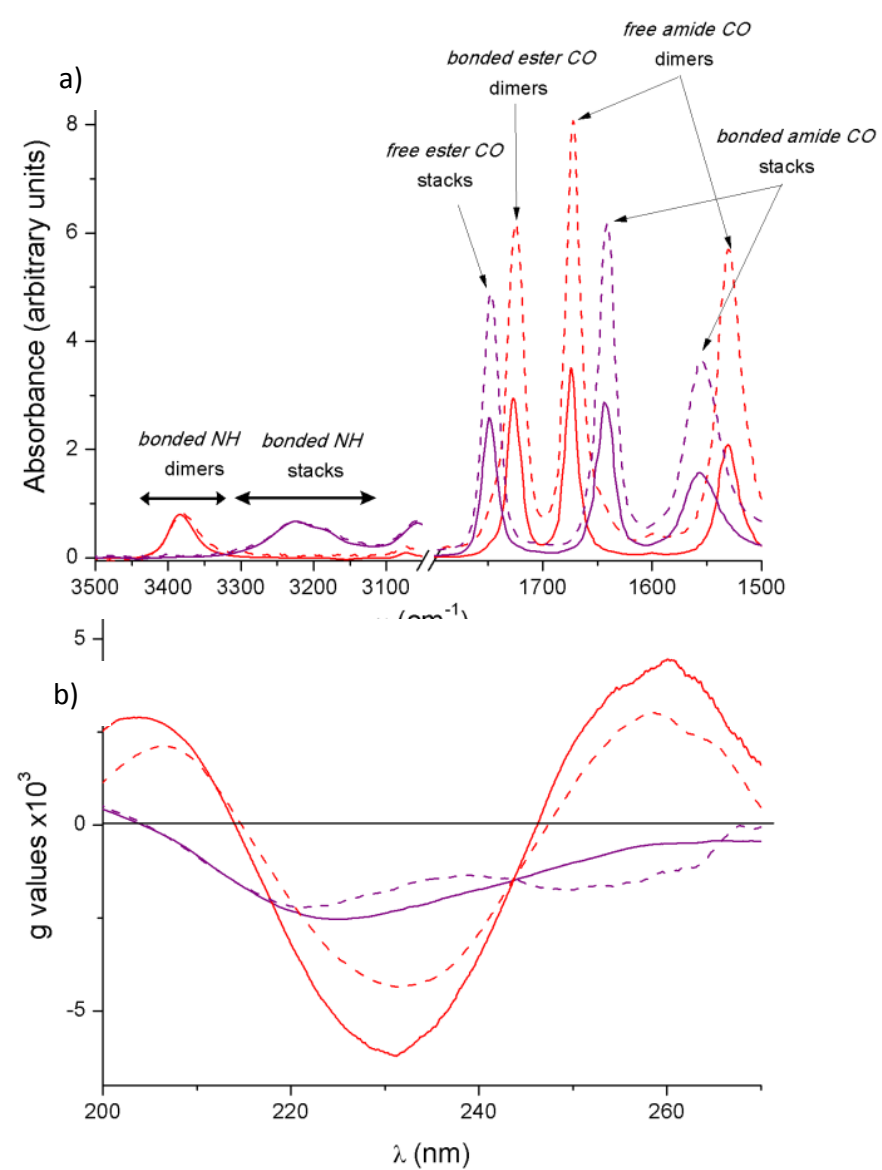

Fig. 12 Spectroscopic signature of stacks of BTA Met (purple) and dimers of BTA
$(R)$-Cha (red) in the bulk (dashed line) and cyclohexane (thick solid line). (a) FT-IR (R)-Cha (red) in the bulk (dashed line) and cyclohexane (thick solid line). (a) FT-IR the N-H stretching frequency. (b) CD spectra plotted according to the Kuhn anisotropy factor $(\mathrm{g}=\Delta \varepsilon / \varepsilon)$.

composed of structurally-similar ester BTAs can exhibit significantly different CD signatures in the bulk (Fig. S7).

An important point is to verify whether, for a given BTA, the molecular structure of the dimers and stacks is the same in the bulk and in cyclohexane. BTA $(\boldsymbol{R})$-Cha and BTA Met form dimers and stacks, respectively, in the two media at the same temperature (Table 2). Both BTAs exhibit virtually identical FT$I R$ and $C D$ spectra in bulk and in cyclohexane (Fig. 12) demonstrating that the molecular structures of their dimers and their stacks are not (or little) affected by the packing (in the bulk) and solvation (in cyclohexane). This observation is obviously not valid for all ester BTAs of Chart 1: e.g. stacks of BTA Phe display quite different CD spectra in the bulk and in solution (Fig. S7 and Fig. S15).

Our CD analyses also reveal that monomers of ester BTAs are weakly $C D$ active in methylcyclohexane and display a similar CD signal whatever the substituent (Fig. 11 and Fig. S28). In rare cases, i.e. for BTA $(\boldsymbol{R})$-Ala and BTA Gly in cyclohexane and for BTA Nle above its clearing temperature in the bulk, we also detected the formation of a hydrogen-bonded species different from stacks and dimers, which we refer to as "short stacks". In short, the spectroscopic and scattering signatures of monomers, dimers, "short stacks" and stacks enable a precise characterization of the self-assemblies formed by ester BTAs. 
Table 2 Self-assembly and macroscopic properties of ester BTAs.

\begin{tabular}{|c|c|c|c|c|c|c|}
\hline & \multicolumn{3}{|c|}{ Assemblies in the bulk } & \multicolumn{3}{|c|}{ Assemblies in cyclohexane } \\
\hline & $\begin{array}{c}\text { structure } \\
\left(20^{\circ} \mathrm{C}\right)\end{array}$ & $T_{c l}\left({ }^{\circ} \mathrm{C}\right)$ & mesophase & structure & $c^{*}$ at $20^{\circ} \mathrm{C}(\mathrm{M})$ & viscosity $^{(d)}$ \\
\hline BTA Gly & unidentified & - (a) & - (a) & dimers+"short stacks" & $-($ b) & fluid \\
\hline BTA $(R)$-Cha & dimers & - (a) & - (a) & dimers & $-($ b) & fluid \\
\hline BTA Phg & stacks & 74 & $\mathrm{Col}_{\text {ho }}^{(\mathrm{c})}$ & dimers & $-(\mathrm{b})$ & fluid \\
\hline BTA Ile & stacks & 131 & $\mathrm{Col}_{\mathrm{ho}}{ }^{(\mathrm{c})}$ & dimers & $-^{(b)}$ & fluid \\
\hline BTA $(R)$-Ala & stacks & 132 & $\mathrm{Col}_{\mathrm{ho}}{ }^{\text {(c) }}$ & dimers+"short stacks"+stacks & $8 \times 10-2$ & viscous $^{+}$ \\
\hline BTA tert-Leu & stacks & 134 & $\mathrm{Col}_{\mathrm{ho}}{ }^{(\mathrm{c})}$ & dimers & $-(b)$ & fluid \\
\hline BTA Nle & stacks & 136 & $\mathrm{Col}_{\text {ho }}$ & dimers & $-^{(\mathrm{b})}$ & fluid \\
\hline BTA Leu & stacks & 138 & $\mathrm{Col}_{\mathrm{ho}}^{\text {(c) }}$ & dimers & $-($ b) & fluid \\
\hline BTA Val & stacks & 158 & $\mathrm{Col}_{\mathrm{ho}}{ }^{(\mathrm{c})}$ & dimers & $--^{(b)}$ & fluid \\
\hline BTA $(R)$-Abu & stacks & 165 & $\mathrm{Col}_{\mathrm{ho}}{ }^{(\mathrm{c})}$ & dimers+stacks & $8 \times 10^{-2}$ & viscous $^{+}$ \\
\hline BTA Phe & stacks & 168 & $\mathrm{Col}_{\mathrm{ho}}$ & dimers+stacks & $4.4 \times 10^{-4}$ & viscous $^{++}$ \\
\hline BTA Met & stacks & 189 & Colho & dimers+stacks & $2.8 \times 10^{-4}$ & gel \\
\hline BTA Aib & stacks & 213 & $\mathrm{Col}_{\text {ho }}$ & dimers+stacks & $3.0 \times 10^{-5}$ & viscous $^{+++}$ \\
\hline
\end{tabular}

Ester BTAs are ranked according to their $T_{c l}$ values. $\mathrm{Col}_{\text {ho }}=$ columnar hexagonal mesophase. (a) No mesophase. (b) No transition between dimers and stacks has been observed in the range of concentrations and temperatures investigated. (c) Col ho presumed by analogy with the mesophase observed for other ester BTAs. (d) Based on the relative viscosity measured in cyclohexane (Fig. S12); the relative viscosity increases in the following order: viscous ${ }^{+}<$viscous $^{++}<$viscous $^{+++}<$gel. $^{\text {. }}$

Our study also shows that the relative stability between stacks and dimers is strongly influenced by very subtle factors such as: i) the nature of the medium (bulk or cyclohexane), ii) the concentration and iii) the nature of the substituent attached on the $\alpha$-carbon. The fact that ester BTAs aggregate into stacks far more easily in the bulk than in solution can be related to several factors: i) the largest assemblies are favoured at high concentration, ii) possible solvation effects or iii) stabilizing intermolecular interactions between adjacent stacks in the bulk. In agreement with the third hypothesis is the well-known ability of BTAs to stack with the amide groups pointing in the same direction within a column. The macrodipole thus generated governs longer-range intermolecular interactions since adjacent columns pack in an antiparallel fashion so as to compensate the dipole moment. ${ }^{42,48,52,54,89-92}$ Such an antiparallel arrangement of the columns stabilizes the rod-like structure in the bulk, as shown in previous studies dealing with the packing of alkyl BTAs. ${ }^{93}$

These intermolecular interactions in the bulk are not sufficiently strong to govern the association of BTA $(\boldsymbol{R})$-Cha and BTA Gly, which aggregate into dimers or unidentified species, respectively, rather than into stacks. All the other ester BTAs of Chart 1 form stacks in the bulk and, for five of them, in cyclohexane (in the range of concentrations and temperatures investigated). It is interesting to note a fair correlation between the stability of the stacks in the bulk (reflected by the clearing temperature, $T_{c l}$ ) and in solution (reflected by the critical concentration, $c^{*}$ ). Four out of the five BTAs able to form stacks in cyclohexane also form the most stable stacks in bulk. Indeed, the stability of the stacks in the bulk decreases in the following order: BTA Aib $\left(T_{c l}=213^{\circ} \mathrm{C}\right)>$ BTA Met $\left(189^{\circ} \mathrm{C}\right)>$ BTA Phe $\left(168^{\circ} \mathrm{C}\right)>$ BTA $(R)$-Abu $\left(165^{\circ} \mathrm{C}\right)$ and exactly the same trend is obtained in cyclohexane for these BTAs. The correlation cannot be applied to the full set of ester
BTAs as illustrated by BTA (R)-Ala, for which $T_{c l}$ is lower than for most ester BTAs ( $9^{\text {th }}$ out of 13 , Table 2 ) and yet belongs to the five ester BTAs able to form stacks in solution.

By looking at the association properties of the ester BTAs in Table 2, it clearly appears that changing the nature of the substituent can be very useful to tune the hydrogen bond pattern of the BTA core. In the bulk, stacks are stable up to $213^{\circ} \mathrm{C}$ (BTA Aib) and dimers are the main species formed by BTA $(R)$-Cha over a large range of temperatures (from $-78^{\circ} \mathrm{C}$ to $182^{\circ} \mathrm{C}$ ). Dimers are also formed by other ester BTAs above their clearing temperatures (Fig. 7). In cyclohexane, stacks are the predominant species for BTA Aib above its critical concentration of $3.0 \times 10^{-5} \mathrm{M}\left(20^{\circ} \mathrm{C}\right)$. Among the family of enantiopure helical rods, the most stable are those formed by BTA Met $\left(c^{*}=2.8 \times 10^{-4} \mathrm{M}\right)$. Dimers appear to be very stable species in solution as they only dissociate at very low concentrations and high temperatures $\left(c^{* *}=7 \times 10^{-6} \mathrm{M}\right.$ and $T^{* *} \approx 80^{\circ} \mathrm{C}$ in the case of BTA Met and BTA Nle).

The macroscopic properties of the ester BTAs are correlated to the structure of their self-assemblies (Table 2). Only ester BTAs that associate into a rod-like structure in the bulk yield a columnar mesophase at the meso/macroscale. Also, only ester BTAs that assemble as long rods in cyclohexane (as determined by SANS and FT-IR analyses, Figs. 8 and S16) form gels or viscous solutions. We note a slight discrepancy between the critical concentration of ester BTAs (which reflects the stability of the rod-like structure in cyclohexane) and the relative viscosity of their cyclohexane solutions. Indeed, the stability of the rod-like structure decreases in the following order: BTA Aib $>$ BTA Met $>$ BTA Phe $>$ BTA $(R)$-Abu $\approx$ BTA $(R)$-Ala whilst the relative viscosity is higher for BTA Met than for BTA Aib and then obeys the same order than the stack stability. We presume that BTA Met forms longer stacks in cyclohexane 


\section{Soft Matter}

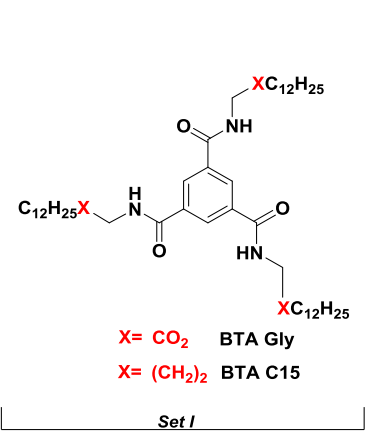

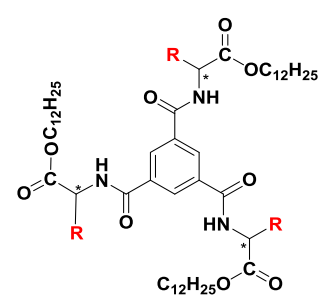

$\mathrm{R}=(R)-\mathrm{CH}_{3} \quad \mathrm{BTA}(R)-\mathrm{Ala}$

$\mathrm{R}=(R)-\mathrm{CH}_{2} \mathrm{CH}_{3}$ BTA $(R)$-Abu $\mathrm{R}=(\mathrm{S})-\mathrm{CH}_{2}\left(\mathrm{CH}_{2}\right)_{2} \mathrm{CH}_{3}$ BTA Nle Set II
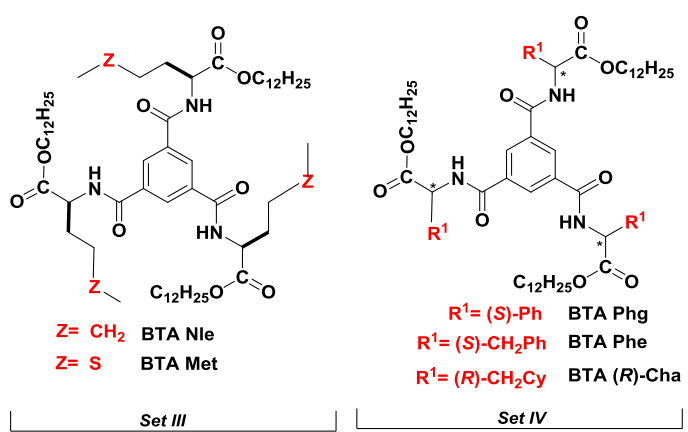

Chart 2 Sets of structurally-similar ester BTAs whose association properties have been compared in order to isolate the influence of a single moiety or atom: the ester function (Set I), the length of the linear alkyl chain (Set II), the sulfur heteroatom (Set III) and the pendant phenyl group (Set IV).

than BTA Aib, despite the fact that the stacks of the latter start growing at a lower concentration.

By studying the association properties of the structurallyrelated ester BTAs of Chart 1, we gain information on how a single atom or a group of atoms located in the side chains can impact the nature and stability of the hydrogen-bonded assemblies. One can deduce the following observations (see the different sets of BTAs that are compared in Chart 2):

Influence of the ester group (Set I, Chart 2): BTA C15 is the alkyl BTA analogue of BTA Gly. Unlike BTA Gly, BTA C15 forms a columnar mesophase $\left(T_{c l}=214^{\circ} \mathrm{C}\right)$ and likely assembles into stacks in cyclohexane. ${ }^{47}$ Clearly, the ester group of BTA Gly prevents it from forming long stacks both in the bulk and in solution. It is expected that the ester group may act as a hydrogen bond acceptor and thus limits the association ability of the ester BTAs of Chart 1. This negative effect is particularly strong for BTA Gly but can be largely compensated by the presence of substituents attached on the $\alpha$-carbon. The origin of the positive influence of these substituents on the assembly properties is not trivial and is commented below.

Influence of the length of the linear alkyl chain attached on the $\alpha$-carbon (Set II): The ability of ester BTAs to aggregate into stacks decreases in the following order in this series: BTA $(\boldsymbol{R})$ Abu > BTA $(R)$-Ala >> BTA Nle > BTA Gly. Indeed, stacks formed by BTA $(\boldsymbol{R})$-Abu are more stable than those of BTA $(\boldsymbol{R})$ Ala and BTA Nle in the bulk and only BTA $(R)$-Abu and BTA $(R)$ Ala are able to form stacks in cyclohexane. Moreover, the stacks formed by BTA $(\boldsymbol{R})$-Ala are less stable than those of BTA $(\boldsymbol{R})$-Abu, as evidenced by the observation of "short stacks" in cyclohexane as intermediate species between the dimers and the long stacks (Fig. 8). Accordingly, our study reveals that the ethyl group constitutes an optimum lateral substituent for the stabilization of the stacks in this series.

Influence of the sulfur heteroatom in BTA Met (Set III): Although BTA Met and BTA Nle are isosteric, these compounds exhibit drastic differences in their assembly properties: i) stacks of BTA Met $\left(T_{c l}=189^{\circ} \mathrm{C}\right)$ are far more stable than those of BTA Nle $\left(T_{c l}=136^{\circ} \mathrm{C}\right)$ in the Col ho phase, ii) BTA Met forms stable stacks in cyclohexane while BTA Nle only forms dimers. Compared to BTA Nle, the ability of BTA Met to aggregate into long and stable stacks can be due to additional weak interactions (in addition to hydrogen bond and aromatic interactions) that stabilize the helical rods. Short-range interactions between the sulfur atom and the carbonyl groups of BTA Met, as detected in the X-ray structure of the BTA derived from (L)-methionine, ${ }^{70}$ might be at the origin of this remarkable stabilization.

Influence of a pendant phenyl group attached on the $\alpha$-carbon (Set IV): Despite the relative bulkiness of its benzyl substituent, BTA Phe forms stable helical rods both in the liquid crystalline state and in cyclohexane. Comparatively, BTA $(\boldsymbol{R})$-Cha is unable to aggregate into stacks. The position of the phenyl group in the side chain is also of importance, as evidenced by the poor stability of the stacks formed by BTA Phg in the liquidcrystalline state and the absence of stacks in cyclohexane. Again, the stability of the stacks formed by BTA Phe likely originates from the presence of additional interactions, here aromatic interactions, in the helical rods, as previously hypothesized by Feringa et al. (ester BTAs) ${ }^{66}$ and Meijer et al. (BTAs extended with dipeptide fragments). ${ }^{72}$

Another observation on the assembly behaviour of the ester BTAs of Chart 1 concerns the fact that, except for BTA Phe, the ester BTAs with bulky groups attached on the $\alpha$-carbon (BTA Val, BTA Leu, BTA Ile, BTA tert-Leu) form stacks with limited stability in the liquid crystalline state $\left(T_{c l}<158^{\circ} \mathrm{C}\right)$ and do not form stacks in cyclohexane. Finally, BTA Aib, i.e., the only investigated ester BTA with a secondary $\alpha$-carbon, forms the most stable stacks of the series both in the liquid crystalline state and in cyclohexane. 
The substituent attached on the $\alpha$-carbon plays a crucial role in dictating the assembly properties of ester BTAs. This is likely due to subtle interactions involving this substituent, which modify the relative energy of stacks and dimers. In the cases of BTA Met and BTA Phe, we hypothesize that these interactions stabilize the stacks, but for other ester BTAs the higher stability of stacks over dimers can be due to interactions that destabilize the dimers or to subtle conformational effects. Clearly, MM/MD calculations performed on the different dimeric and rod-like structures may give a more precise picture of the exact role played by the lateral substituents in the assemblies. The molecular structure of the ester-bonded dimer, i.e. the molecular arrangement of the monomers and the hydrogen-bond pattern, have been established through simulation of its CD spectrum (Fig. 5a). This structure will be helpful for such future modelling studies.

\section{Conclusions}

We have studied the influence of the substituent(s) attached on the $\alpha$-carbon on the self-assembly behaviour of ester BTAs of Chart 1 . The spectroscopic and scattering signatures of the self-assemblies formed by ester BTAs: dimers, "short stacks" and stacks have been established as well as that of the monomer. This characterization is crucial in order to prevent misleading assignment of hydrogen-bonded species formed by ester BTAs and structurally-related BTAs. Our study stresses the role played by the substituent(s) on dictating the nature (ester-bonded dimers or stacks) and stability of the hydrogenbonded assemblies formed by ester BTAs in the bulk and in cyclohexane. A trend is obtained between the stability of the stacks in the bulk and in cyclohexane: four out of the five ester BTAs (BTA Aib, BTA Met, BTA Phe, BTA $(R)$-Ala and BTA $(R)$ Abu) that are able to aggregate into stacks in cyclohexane in the range of temperatures and concentrations investigated also form the most stable stacks in the bulk. Except for BTA Gly and BTA $(\boldsymbol{R})$-Cha, all the ester BTAs of Chart 1 form a rod-like structure in the bulk which is at the origin of the $\mathrm{Col}_{\text {ho }}$ mesophase observed above their melting temperature. Additionally, only the five ester BTAs that aggregate into long stacks in cyclohexane yield viscous solutions or gels. The relative stability between stacks and ester-bonded dimers can thus be precisely tuned by means of the substituent(s) attached on the $\alpha$-carbon, which in turn dictates the macroscopic properties exhibited by the respective ester BTAs. Our systematic study also reveals the subtle influence of a single atom or a group of atoms on the relative stability of the dimeric and rod-like structures. The modelled structure of the ester-bonded dimer that is consistent with all the experimental data will be helpful for a better understanding of the origin of these subtle effects. A precise control of the assembly properties of the BTA core will be crucial for the future development of functional BTA supramolecular polymers.

\section{Acknowledgements}

This work was supported by the French Agence Nationale de la Recherche (project ANR-13-BS07-0021 SupraCatal). The GDR 3712 Chirafun is also acknowledged for allowing a collaborative network between the partners of this project. Jacques Jestin (LLB, Saclay) is acknowledged for assistance with SANS experiments, and Fabrice Mathevet (UPMC, Paris) for his help in the achievement of POM analyses. Research in Mons is supported by the Science Policy Office of the Belgian Federal Government (BELSPO PAI 7/5) and FNRS-FRFC. D.B. is FNRS research director.

\section{Notes and references}

¥ BTA (R)-Met was chosen for this fingerprint characterization, instead of its previously investigated enantiomer BTA Met, since it allows us to point out the almost identical CD spectra displayed by BTA $(\boldsymbol{R})$-Met and BTA C8*. Accordingly, BTA $(\boldsymbol{R})$-Nle was selected for the dimeric structure for consistency. As expected, the $C D$ spectra of BTA Met and BTA Nle are mirror images of those displayed by their respective enantiomers (Fig. S3).

$\S$ Heating can be needed for ester BTAs which form gel or viscous solutions in order to ensure that the samples are homogeneous.

$\S \S$ Solutions of BTA Gly in cyclohexane ( $c \geq 10 \mathrm{wt} \%)$ are metastable as a precipitate is formed after a few days at room temperature.

$\S \S \S$ In our previous study (ref. 77), we observed no CD signal for ester BTAs in ethanol and we conclude that "ester BTA monomers are not CD active". It is likely that the average conformation of ester BTA monomers is different in methylcyclohexane at high temperature and in ethanol at room temperature and that only the conformation in methylcyclohexane is $\mathrm{CD}$ active.

1. L. Brunsveld, B. J. B. Folmer, E. W. Meijer and R. P. Sijbesma, Chem. Rev., 2001, 101, 4071-4097.

2. L. Bouteiller, Adv. Polym. Sci., 2007, 207, 79-112.

3. T. F. A. De Greef, M. M. J. Smulders, M. Wolffs, A. P. H. J. Schenning, R. P. Sijbesma and E. W. Meijer, Chem. Rev., 2009, 109, 5687-5754.

4. T. Aida, E. W. Meijer and S. I. Stupp, Science, 2012, 335, 813817.

5. J. H. K. K. Hirschberg, L. Brunsveld, A. Ramzi, J. A. J. M. Vekemans, R. P. Sijbesma and E. W. Meijer, Nature, 2000, 407, 167-170.

6. L. Brunsveld, B. G. G. Lohmeijer, J. A. J. M. Vekemans and E. W. Meijer, Chem. Commun., 2000, 2305-2306.

7. H. Fenniri, M. Packiarajan, K. L. Vidale, D. M. Sherman, K. Hallenga, K. V. Wood and J. G. Stowell, J. Am. Chem. Soc., 2001, 123, 3854-3855.

8. L. Brunsveld, J. A. J. M. Vekemans, J. H. K. K. Hirschberg, R. P. Sijbesma and E. W. Meijer, Proc. Natl. Acad. Sci. USA, 2002, 99, 4977-4982.

9. N. Chebotareva, P. H. H. Bomans, P. M. Frederik, N. A. J. M. Sommerdijk and R. P. Sijbesma, Chem. Commun., 2005, 49674969.

10. E. Obert, M. Bellot, L. Bouteiller, F. Andrioletti, C. LehenFerrenbach and F. Boué, J. Am. Chem. Soc., 2007, 129, 1560115605.

11. C. M. A. Leenders, L. Albertazzi, T. Mes, M. M. E. Koenigs, A. R. A. Palmans and E. W. Meijer, Chem. Commun., 2013, 49, 1963-1965.

12. M. B. Baker, L. Albertazzi, I. K. Voets, C. M. A. Leenders, A. R. A. Palmans, G. M. Pavan and E. W. Meijer, Nature Commun., 2015, 6, 6234-6246. 
13. C. M. A. Leenders, M. B. Baker, I. A. B. Pijpers, R. P. M. Lafleur, L. Albertazzi, A. R. A. Palmans and E. W. Meijer, Soft Matter, 2016, 12, 2887-2893.

14. C. M. A. Leenders, G. Jansen, M. M. M. Frissen, R. P. M. Lafleur, I. K. Voets, A. R. A. Palmans and E. W. Meijer, Chem. Eur. J., 2016, 22, 4608-4615.

15. F. Ouhib, M. Raynal, B. Jouvelet, B. Isare and L. Bouteiller, Chem. Commun., 2011, 47, 10683-10685.

16. M. Tharcis, T. Breiner, J. Belleney, F. Boue and L. Bouteiller, Polymer Chem., 2012, 3, 3093-3099.

17. A. Pal, S. Karthikeyan and R. P. Sijbesma, J. Am. Chem. Soc., 2010, 132, 7842-7843.

18. O. Colombani, C. Barioz, L. Bouteiller, C. Chaneac, L. Fomperie, F. Lortie and H. Montes, Macromolecules, 2005, 38, 1752-1759.

19. H. Kautz, D. J. M. van Beek, R. P. Sijbesma and E. W. Meijer, Macromolecules, 2006, 39, 4265-4267.

20. J. Roosma, T. Mes, P. Leclere, A. R. A. Palmans and E. W. Meijer, J. Am. Chem. Soc., 2008, 130, 1120-1121.

21. C. F. C. Fitié, I. Tomatsu, D. Byelov, W. H. de Jeu and R. P. Sijbesma, Chem. Mater., 2008, 20, 2394-2404.

22. M. García-Iglesias, B. F. M. de Waal, I. de Feijter, A. R. A Palmans and E. W. Meijer, Chem. Eur. J., 2015, 21, 377-385.

23. P. Y. W. Dankers, M. C. Harmsen, L. A. Brouwer, M. J. A. Van Luyn and E. W. Meijer, Nature Mat., 2005, 4, 568-574.

24. A. T. Haedler, K. Kreger, A. Issac, B. Wittmann, M. Kivala, N. Hammer, J. Köhler, H.-W. Schmidt and R. Hildner, Nature, 2015, 523, 196-200.

25. M. Raynal, F. Portier, P. W. N. M. van Leeuwen and L. Bouteiller, J. Am. Chem. Soc., 2013, 135, 17687-17690.

26. M. de Torres, R. van Hameren, R. J. M. Nolte, A. E. Rowan and J. A. A. W. Elemans, Chem. Commun., 2013, 49, 1078710789.

27. E. Huerta, B. van Genabeek, B. A. G. Lamers, M. M. E. Koenigs, E. W. Meijer and A. R. A. Palmans, Chem. Eur. J., 2015, 21, 3682-3690

28. L. N. Neumann, M. B. Baker, C. M. A. Leenders, I. K. Voets, R. P. M. Lafleur, A. R. A. Palmans and E. W. Meijer, Org. Biomol. Chem., 2015, 13, 7711-7719.

29. A. Desmarchelier, X. Caumes, M. Raynal, A. Vidal-Ferran, P. W. N. M. van Leeuwen and L. Bouteiller, J. Am. Chem. Soc., 2016 138, 4908-4916.

30. For a review on the relationship between the molecular structure of bisurea monomers and the structure of their supramolecular polymers see: B. Isare, S. Pensec, M. Raynal and L. Bouteiller, C. R. Chimie, 2016, 19, 148-156 and references therein.

31. In references 31-33 parameters influencing the gelation capabilities of structurally-similar low molecular-weight gelators are discussed: R. G. Weiss, J. Am. Chem. Soc., 2014, 136, 75197530

32. D. M. Zurcher and A. J. McNeil, J. Org. Chem., 2015, 80, 2473-2478.

33. J. Bonnet, G. Suissa, M. Raynal and L. Bouteiller, Soft Matter, 2015, 11, 2308-2312.

34. T. Mes, M. M. J. Smulders, A. R. A. Palmans and E. W. Meijer, Macromolecules, 2010, 43, 1981-1991.

35. Y. Nakano, T. Hirose, P. J. M. Stals, E. W. Meijer and A. R. A. Palmans, Chem. Sci., 2012, 3, 148-155.

36. B. Isare, G. Pembouong, F. Boue and L. Bouteiller, Langmuir, 2012, 28, 7535-7541.

37. I. Giannicchi, B. Jouvelet, B. Isare, M. Linares, A. Dalla Cort and L. Bouteiller, Chem. Commun., 2014, 50, 611-613.

38. M. Dirany, V. Ayzac, B. Isare, M. Raynal and L. Bouteiller, Langmuir, 2015, 31, 11443-11451.

39. S. Cantekin, T. F. A. de Greef and A. R. A. Palmans, Chem. Soc. Rev., 2012, 41, 6125-6137.
40. Y. Yasuda, E. lishi, H. Inada and Y. Shirota, Chem. Lett., 1996, 575-576.

41. K. Hanabusa, C. Koto, M. Kimura, H. Shirai and A. Kakehi, Chem. Lett., 1997, 429-430.

42. T. Shikata, Y. Kuruma, A. Sakamoto and K. Hanabusa, J. Phys. Chem. B, 2008, 112, 16393-16402.

43. H. Cao, P. F. Duan, X. F. Zhu, J. Jiang and M. H. Liu, Chem. Eur. J., 2012, 18, 5546-5550.

44. Z. C. Shen, T. Y. Wang and M. H. Liu, Angew. Chem. Int. Ed., 2014, 53, 13424-13428.

45. Y. Ishioka, N. Minakuchi, M. Mizuhata and T. Maruyama, Soft Matter, 2014, 10, 965-971.

46. Y. Matsunaga, Y. Nakayasu, S. Sakai and M. Yonenaga, Mol. Cryst. Liq. Cryst., 1986, 141, 327-333.

47. Y. Matsunaga, N. Miyajima, Y. Nakayasu, S. Sakai and M. Yonenaga, Bull. Chem. Soc. Jpn., 1988, 61, 207-210.

48. M. P. Lightfoot, F. S. Mair, R. G. Pritchard and J. E. Warren, Chem. Commun., 1999, 1945-1946.

49. J. J. van Gorp, J. A. J. M. Vekemans and E. W. Meijer, J. Am. Chem. Soc., 2002, 124, 14759-14769.

50. M. L. Bushey, T. Q. Nguyen and C. Nuckolls, J. Am. Chem. Soc., 2003, 125, 8264-8269.

51. P. J. M. Stals, M. M. J. Smulders, R. Martín-Rapún, A. R. A Palmans and E. W. Meijer, Chem. Eur. J., 2009, 15, 2071-2080.

52. A. Timme, R. Kress, R. Q. Albuquerque and H. W. Schmidt, Chem. Eur. J., 2012, 18, 8329-8339.

53. C. Invernizzi, C. Dalvit, H. Stoeckli-Evans and R. Neier, Eur. J. Org. Chem., 2015, 5115-5127.

54. C. F. C. Fitié, W. S. C. Roelofs, M. Kemerink and R. P. Sijbesma, J. Am. Chem. Soc., 2010, 132, 6892-6893.

55. M. Blomenhofer, S. Ganzleben, D. Hanft, H. W. Schmidt, M. Kristiansen, P. Smith, K. Stoll, D. Mader and K. Hoffmann, Macromolecules, 2005, 38, 3688-3695.

56. N. Mohmeyer, N. Behrendt, X. Q. Zhang, P. Smith, V. Altstadt, G. M. Sessler and H. W. Schmidt, Polymer, 2007, 48 1612-1619.

57. F. Abraham and H. W. Schmidt, Polymer, 2010, 51, 913-921.

58. F. Richter and H. W. Schmidt, Macromol. Mat. Eng., 2013 298, 190-200.

59. P. Besenius, G. Portale, P. H. H. Bomans, H. M. Janssen, A. R A. Palmans and E. W. Meijer, Proc. Natl. Acad. Sci. USA, 2010, 107, 17888-17893.

60. P. Besenius, K. P. van den Hout, H. M. H. G. Albers, T. F. A. de Greef, L. L. C. Olijve, T. M. Hermans, B. F. M. de Waal, P. H. H. Bomans, N. A. J. M. Sommerdijk, G. Portale, A. R. A. Palmans, M. H. P. van Genderen, J. A. J. M. Vekemans and E. W. Meijer, Chem. Eur. J., 2011, 17, 5193-5203.

61. P. Besenius, J. L. M. Heynens, R. Straathof, M. M. L. Nieuwenhuizen, P. H. H. Bomans, E. Terreno, S. Aime, G. J. Strijkers, K. Nicolay and E. W. Meijer, Contrast Media Mol. Imaging, 2012, 7, 356-361.

62. I. de Feijter, P. Besenius, L. Albertazzi, E. W. Meijer, A. R. A. Palmans and I. K. Voets, Soft Matter, 2013, 9, 10025-10030.

63. S. H. Jung, J. Jeon, H. Kim, J. Jaworski and J. H. Jung, J. Am. Chem. Soc., 2014, 136, 6446-6452.

64. D. Ranganathan, S. Kurur, R. Gilardi and I. L. Karle, Biopolymers, 2000, 54, 289-295.

65. P. P. Bose, M. G. B. Drew, A. K. Das and A. Banerjee, Chem Commun., 2006, 3196-3198.

66. M. de Loos, J. H. van Esch, R. M. Kellogg and B. L. Feringa, Tetrahedron, 2007, 63, 7285-7301.

67. M. A. J. Veld, D. Haveman, A. R. A. Palmans and E. W. Meijer Soft Matter, 2011, 7, 524-531.

68. G. Srinivasulu, B. Sridhar, K. R. Kumar, B. Sreedhar, V. Ramesh, R. Srinivas and A. C. Kunwar, J. Mol. Struct., 2011, 1006 180-184. 
69. S. Cantekin, H. M. M. ten Eikelder, A. J. Markvoort, M. A. J. Veld, P. A. Korevaar, M. M. Green, A. R. A. Palmans and E. W. Meijer, Angew. Chem. Int. Ed., 2012, 51, 6426-6431.

70. P. Jana, A. Paikar, S. Bera, S. K. Maity and D. Haldar, Org. Lett., 2014, 16, 38-41.

71. I. L. Karle and D. Ranganathan, J. Peptide. Res., 2005, 65, 6570.

72. K. P. van den Hout, R. Martín-Rapún, J. A. J. M. Vekemans and E. W. Meijer, Chem. Eur. J., 2007, 13, 8111-8123.

73. R. Gutiérrez-Abad, O. Illa and R. M. Ortuño, Org. Lett., 2010, 12, 3148-3151.

74. H. Frisch, J. P. Unsleber, D. Ludeker, M. Peterlechner, G. Brunklaus, M. Waller and P. Besenius, Angew. Chem. Int. Ed. 2013, 52, 10097-10101.

75. Y. T. Dai, X. Zhao, X. Y. Su, G. Y. Li and A. Zhang, Macromol. Rapid. Commun., 2014, 35, 1326-1331.

76. H. Frisch, Y. Nie, S. Raunser and P. Besenius, Chem. Eur. J., 2015, 21, 3304-3309.

77. A. Desmarchelier, M. Raynal, P. Brocorens, N. Vanthuyne and L. Bouteiller, Chem. Commun., 2015, 51, 7397-7400.

78. M. Prashad, D. Har, B. Hu, H. Y. Kim, O. Repic and T. J. Blacklock, Org. Lett., 2003, 5, 125.

79. G. A. Hembury, V. V. Borovkov and Y. Inoue, Chem. Rev., 2008, 108, 1-73.

80. M. M. J. Smulders, A. P. H. J. Schenning and E. W. Meijer, J. Am. Chem. Soc., 2008, 130, 606-611.

81. M. Wegner, D. Dudenko, D. Sebastiani, A. R. A. Palmans, T. F. A. de Greef, R. Graf and H. W. Spiess, Chem. Sci., 2011, 2, 20402049.

82. R. van Hameren, A. M. van Buul, D. Visser, R. K. Heenan, S. M. King, A. E. Rowan, R. J. M. Nolte, W. Pyckhout-Hintzen, J. A A. W. Elemans and M. C. Feiters, Soft Matter, 2014, 10, 96889694.

83. M. T. Scerba, A. F. DeBlase, S. Bloom, T. Dudding, M. A Johnson and T. Lectka, J. Phys. Chem. A, 2012, 116, 3556-3560. 84. S. I. Kirin, H. B. Kraatz and N. Metzler-Nolte, Chem. Soc. Rev., 2006, 35, 348-354.

85. A. C. Laungani and B. Breit, Chem. Commun., 2008, 844-846.

86. Z. Kokan and S. I. Kirin, RSC Adv., 2012, 2, 5729-5737.

87. Z. Kokan and S. I. Kirin, Eur. J. Org. Chem., 2013, 2013, 81548161.

88. Z. Kokan, Z. Glasovac, M. M. Elenkov, M. Gredicak, I. Jeric and S. I. Kirin, Organometallics, 2014, 33, 4005-4015.

89. A. Sakamoto, D. Ogata, T. Shikata, O. Urakawa and K. Hanabusa, Polymer, 2006, 47, 956-960.

90. C. Kulkarni, S. K. Reddy, S. J. George and S. Balasubramanian, Chem. Phys. Lett., 2011, 515, 226-230.

91. R. Q. Albuquerque, A. Timme, R. Kress, J. Senker and H. W. Schmidt, Chem. Eur. J., 2013, 19, 1647-1657.

92. K. K. Bejagam, G. Fiorin, M. L. Klein and S. Balasubramanian, J. Phys. Chem. B, 2014, 118, 5218-5228.

93. M. Kristiansen, P. Smith, H. Chanzy, C. Baerlocher, V. Gramlich, L. McCuskcr, T. Weber, P. Pattison, M. Blomenhofer and H. W. Schmidt, Cryst. Growth Des., 2009, 9, 2556-2558. 